\section{Optimal inductor design for nanofluid heating characterisation}

Optimal inductor design

Roberta Bertani and Flavio Ceretta Industrial Engineering, University of Padova, Padova, Italy

Paolo Di Barba

Department of Electrical Engineering, University of Pavia, Pavia, Italy

Fabrizio Dughiero, Michele Forzan, Rino Antonio Michelin, Paolo Sgarbossa and Elisabetta Sieni Industrial Engineering, University of Padova, Padova, Italy, and Federico Spizzo

Physics and Earth Sciences and CNISM, University of Ferrara, Ferrarra, Italy
Received 3 November 2014 Revised 9 February 2015 Accepted 5 March 2015

\section{Abstract}

Purpose - Magnetic fluid hyperthermia experiment requires a uniform magnetic field in order to control the heating rate of a magnetic nanoparticle fluid for laboratory tests. The automated optimal design of a real-life device able to generate a uniform magnetic field suitable to heat cells in a Petri dish is presented. The paper aim to discuss these issues.

Design/methodology/approach - The inductor for tests has been designed using finite element analysis and evolutionary computing coupled to design of experiments technique in order to take into account sensitivity of solutions.

Findings - The geometry of the inductor has been designed and a laboratory prototype has been built. Results of preliminary tests, using a previously synthesized and characterized magneto fluid, are presented. Originality/value - Design of experiment approach combined with evolutionary computing has been used to compute the solution sensitivity and approximate a 3D Pareto front. The designed inductor has been tested in an experimental set-up.

Keywords Multi-objective optimization, Finite element analysis, Sensitivity analysis, Magnetic fluid hyperthermia, Magnetic nanoparticles, Uniform magnetic field

Paper type Research paper

\section{Introduction}

Magnetic fluid hyperthermia (MFH) is a cancer therapy that uses a magnetic nanoparticle (NP) fluid to heat locally tumor cells (Hildebrandt et al., 2002; Goya et al., 2003, 2013; Krishnan, 2010). The first device applied for this therapy is described in Gneveckow et al. (2004) and Jordan et al. (1999, 2001). At the time being, a large variety of magnetic fluids exists (Roca et al., 2009; Sun et al., 2003). In order to verify the magnetic fluid heating capability in biological systems, the synthesized NPs have to be tested on cell cultures (Jordan, 1999). The geometry of the device to generate the magnetic field must be suitably designed in order to achieve a good uniformity in the region where cells are placed. The design of the magnetic field source can be driven by means of various parametric

Authors are grateful to Dr Federico Caicci with the Biology Dept. of Padova University for TEM images, and to the MSc candidates Ms Federica Savarino and Mr Sergio Calasso for the help on experiments. This work has been supported by a grant "Progetto di Ateneo" of the Padova University (CPDA114144). 
or non-parametric optimization algorithms (Barba et al., 2013; Di Barba et al., 2010, 2012a, b, c, 2013, 2014). In the paper, the optimization of the magnetic field in a device to heat a NP magnetic fluid, previously injected inside cells cultured in a Petri dish, is presented. The inductor design is driven by means of NSGA-DOE algorithm, a multi-objective optimization method NSGA based that incorporates a set of uncertain parameters (Di Barba et al., 2014). In fact, the issue of handling a multi-dimensional solution space in a cost-effective way is a prerequisite for selecting a specific algorithm (Riganti Fulginei and Salvini, 2007). In computational electromagnetism, optimization problems are characterized by one or more objective functions which are known in a numerical form only; usually, their computation rely of 2D or 3D finite-element models of the device or system under study. Therefore, the standard assumption of convexity cannot be invoked by any means and the use of gradient-free algorithms is recommended. Despite the statistical performance of an optimization algorithm across the whole class of solvable problem is the same (Wolpert and Macready, 1997), the evolutionary computing algorithms have proven to be effective in identifying the region of global optimum both for both single-objective and multi-objective problems.

In the paper, a 3D objective space is investigated; in particular, three objective functions are minimized: $\left(f_{1}\right)$ the inhomogeneity of the magnetic field strength in the bottom region of the Petri dish, $\left(\mathrm{f}_{2}\right)$ the sensitivity of the magnetic field inhomogeneity and $\left(f_{3}\right)$ either the voltage at inductor ends or maximizing the magnetic field value in the bottom of Petri dish. Finally, the designed device has been realized and tested using NP suspensions produced by the chemical laboratory of the Department of Industrial Engineering of Padova University. Nanofluids have been previously characterized in terms of both physical and chemical properties and also in term of heat generation at a given intensity of time-varying magnetic field.

\section{Heating problem}

In $\mathrm{MFH}$ the heat is generated by the interaction of a magnetic fluid, a suspension of superparamagnetic nanometric particles in a fluid, and a time-varying magnetic field. The magnetic field allows the rotation of both the magnetic moments and entire NPs in the biological medium. The power density (in $\left(\mathrm{W} / \mathrm{m}^{3}\right)$ ) generated in the nanofluid can be evaluated by means of the following relation (Rosensweig, 2002):

$$
P=\mu_{0} \pi \chi^{\prime \prime}(H) f H^{2}
$$

where $\mu_{0}$ is the magnetic permeability of the vacuum, $f$ the magnetic field frequency, $\chi^{\prime \prime}$ the magnetic susceptibility of the NPs, $H$ the root means square amplitude of magnetic field in $\left(\mathrm{Am}^{-1}\right)$. Moreover, also the magnetic susceptibility $\chi^{\prime \prime}$ (dimensionless) is a function of the magnetic field $H$ and Langevin's parameter, $\xi$ (Rosensweig, 2002):

$$
\chi^{\prime \prime}=\frac{\omega \tau}{\left[1+(\omega \tau)^{2}\right]} \chi_{0}
$$

where $\omega$ is the angular frequency of $H$ in $\left(\mathrm{s}^{-1}\right), \tau$ the relaxation time, in (s), of the NPs due to Neel, $\tau_{\mathrm{N}}$, and Brown, $\tau_{\mathrm{B}}$, relaxation time constants, in (s), such that $\tau^{-1}=\tau_{N}^{-1}+\tau_{B}^{-1}$ (Rosensweig, 2002). The Brown relaxation time is correlated to the NP rotation in the suspension media and depends on the medium viscosity, $\eta$ in $(\mathrm{Pa} \cdot \mathrm{s})$ :

$$
\tau_{B}=3 \eta V_{H}\left(k_{B} T\right)^{-1} \text { and } \tau_{N}=\tau_{0} e^{\frac{K V m}{k_{B} T}}
$$


where $k_{B}$ is the Boltzman constant $\left(1.38 \times 10^{-23}\left(\mathrm{JK}^{-1}\right)\right), T$ the temperature in $(\mathrm{K}), V_{m}$ is the volume of the magnetic core with diameter $D$ in $\left(\mathrm{m}^{3}\right), V_{H}$ is the hydrodynamic volume considering a cover layer with a thick $\delta$ in $\left(\mathrm{m}^{3}\right), \quad\left(V_{m}=4 \pi(D / 2)^{3} / 3\right.$, $V_{H}=\left(1+\delta(D / 2)^{-1}\right)^{3} V_{m}$ ). Whereas $\chi_{0}$ (dimensionless) is:

$$
\chi_{0}=\frac{3 \chi_{i}}{\xi} \cdot\left(\operatorname{coth} \xi-\frac{1}{\xi}\right)
$$

Optimal inductor design

with

$$
\xi=\frac{\mu_{0} M_{d} H V_{m}}{k_{B} T} \text { and } \chi_{i}=\frac{\mu_{0} \phi M_{d}^{2} V_{m}}{3 k T}
$$

where $M_{d}$ is the domain magnetization of the magnetic material in $\left(\mathrm{Am}^{-1}\right)$ and $\phi$ the fraction (dimensionless) of the magnetic NPs in the suspension (Rosensweig, 2002). In particular, $\xi$ and $\chi_{i}$ are dimensionless quantities. Equation (1) evidences the dependence of the power density $P$ on the square of the magnetic field strength. As a consequence, it is necessary to have a homogeneous magnetic field strength in the volume where there are the NPs. The optimal design of the inductor to generate the magnetic field used in the cell cultures experiments is required in order to apply on the cell surface the same intensity of magnetic field and obtain an uniform heating.

\section{Direct problem}

The direct problem has been solved by means of $2 \mathrm{D}$ models and coupled with an optimization algorithm in order to find the geometry that improves the magnetic field uniformity. Finally, the optimal solution found has been modeled also in a 3D domain to assess the end effects of the inductor on the magnetic field uniformity.

\section{$3.12 D$ analysis}

Figure 1(a) shows the cross section of the 2D axy-symmetric geometry of the device. The Petri dish is placed in a thermally insulated box where a water flow maintains the temperature of the system at $37^{\circ} \mathrm{C}$. The magnetic field device is a two-turn inductor with five ferrite blocks placed as in Figure 1(a) in order to concentrate the magnetic flux lines. The ferrite elements have been divided into five blocks for two reasons: first of all, the uniformity of magnetic field in the region of interest can be improved by varying independently the vertical position of each ferrite block in the upper part of the device; moreover, the sizes of blocks that have been considered correspond to commercially available parts. Ferrite elements are made of non-linear material (i.e. initial relative permeability between 800 and 4,300, saturation magnetic flux density between 0.39 and $0.5 \mathrm{~T}$ ). The magnetic field is solved in time-harmonics using a finite element code (FLUX, n.d.). In particular, the problem is solved in terms of phasor of magnetic vector potential, $A$, coupled with the electric scalar potential, V. When the Coulomb gauge is applied to the magnetic vector potential, i.e. $\nabla \cdot A=0$, the following coupled equations are solved (Di Barba et al., 2008, 2012; Binns et al., 1992):

$$
\nabla \times \frac{1}{\mu} \nabla \times A+j \omega \mu \frac{1}{\rho} A=-\frac{1}{\rho} \nabla \mathrm{V}
$$


EC

32,7

4

(a)

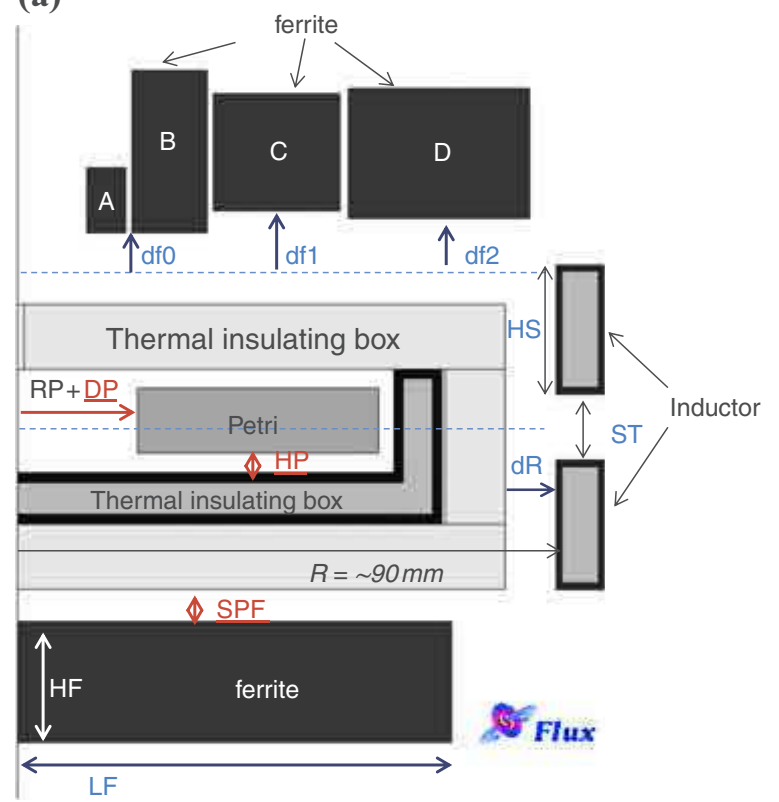

(b)

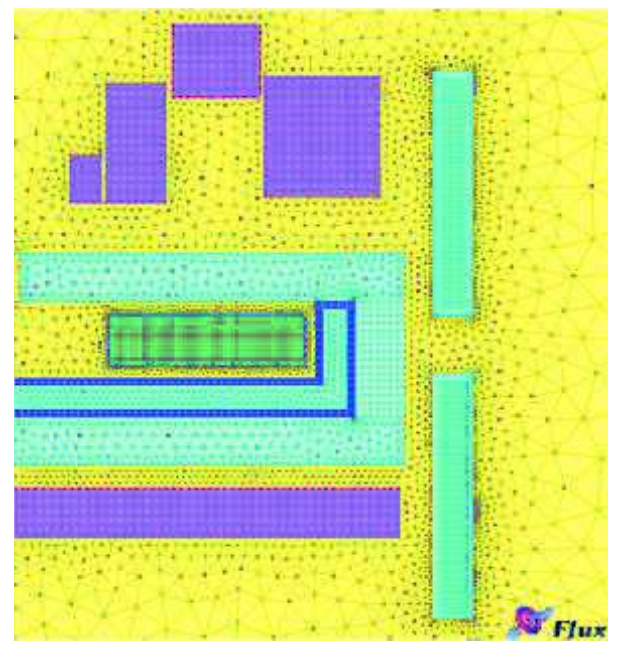

Figure 1.

(a)Geometry of the device with design variables and uncertain parameters (parameters underlined);

(b) detail of a typical mesh; (c) 3D geometry (c)

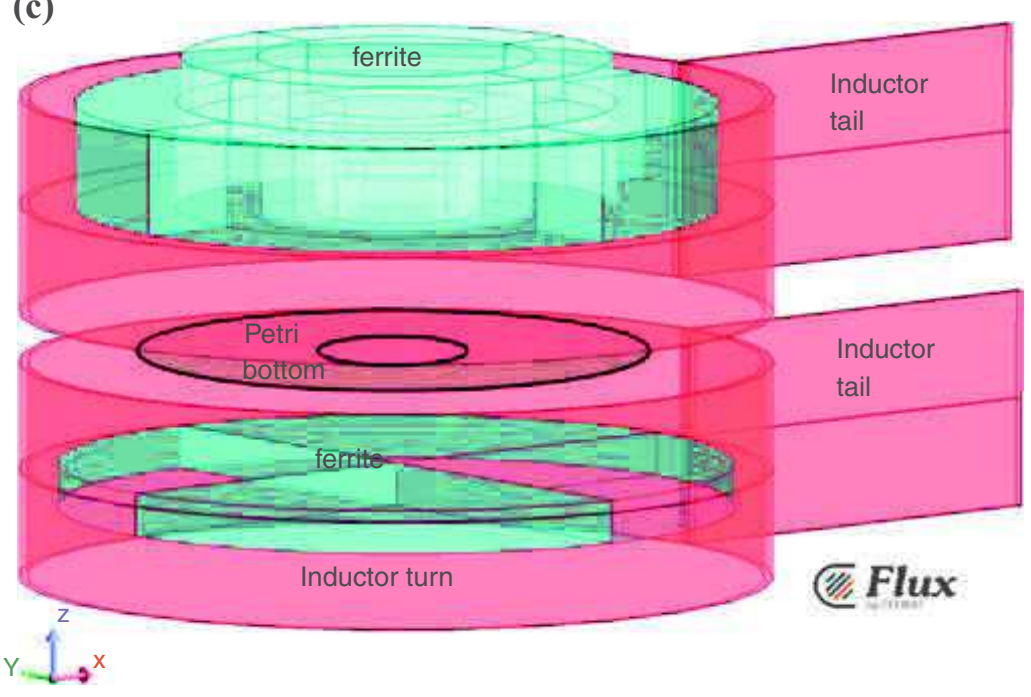

$$
\nabla \cdot \frac{1}{\rho}(j \omega \mu A+\nabla V)=0
$$

with $\mu$ is the material permeability, $\omega$ field pulsation and $\rho$ material resistivity for copper turns.

The problem has been studied supplying the inductor by imposing either a current or a voltage. A typical mesh (Figure 1(b)) is composed of 23,000 nodes and 13,000 second-order elements.

\section{$3.23 D$ analysis}

Results obtained after the optimization process based on 2D models have been assessed a posteriori by means of the 3D model shown in Figure1(c). This model includes the two 
inductor turns, represented as two circular bends, and the ferrite elements. The model incorporates also the inductor ends, connected to the power supply. This model disregards Petri and thermal insulating box, because they have no influence on the magnetic field computation. The aim of this model is to assess the influence of the inductor ends on the uniformity of the magnetic field distribution. The problem is solved again in time-harmonics conditions using finite element analysis. The 3D solutions have been obtained by applying the scalar potential formulation in terms of scalar magnetic potential, $\Phi$, and vector electric potential $T$. The electromagnetic solution is coupled with an external circuit to apply the same current to each turn of the inductor. This formulation allows to compute the magnetic field $\boldsymbol{H}$ and current density $\boldsymbol{J}$ as (Biro et al., 2004):

$$
\begin{gathered}
H=\boldsymbol{T}+\boldsymbol{T}_{0}-\nabla \Phi \\
\boldsymbol{J}=\nabla \times \boldsymbol{T}+\nabla \times \boldsymbol{T}_{0}
\end{gathered}
$$

$\boldsymbol{T}_{O}$ is an impressed electric vector potential depending on the imposed current in the coil that is computed as Biot-Savart field.

The ferrites are non-conductive regions with non-linear magnetic properties, where $\nabla \times \boldsymbol{H}=0$ and the solution is obtained from the total scalar magnetic $\Phi$, by solving:

$$
\nabla \cdot(\mu(\boldsymbol{H}) \nabla \Phi)=0
$$

In the inductor, the reduced scalar magnetic potential is coupled with the electric vector potentials, $\boldsymbol{T}$ and $\boldsymbol{T}_{0}$ is calculated by means of Biot-Savart law. The air region that encompasses the active parts in the model is solved in terms of reduced scalar potential. The appropriate coupling conditions between total and reduced scalar potential are applied on the interfaces between air and ferrite (Aliferov et al., 2010; Biro et al., 2004; Meunier, 2008).

The 3D mesh has $5.2 \times 10^{5}$ nodes and $3.0 \times 10^{6}$ first-order volume elements.

\section{Inverse problem}

The optimization problem aims at minimizing the inhomogeneity of the magnetic field, $\mathrm{H}$, on the bottom of the Petri dish $\left(f_{1}\right)$, evaluated as in Di Barba et al. (2014a, b, in press a, b) with a tolerance interval of $\pm 10 \mathrm{~A} / \mathrm{m}$. The $\left(f_{1}\right)$ is evaluated in a fixed grid of sampling points which does not change during the optimization process and accounts for the number of points that satisfy the "proximity criterion". Specifically, the value of $\left(f_{1}\right)$ is the minimum number of points of the fixed grid for which the magnetic field strength is out of the prescribed tolerance interval. The $\left(f_{2}\right)$ is the sensitivity of $\left(f_{1}\right)$ with respect to a set of uncertain parameters, which are different from the design variables, computed by means of the NSGA-DOE algorithm (Di Barba et al., 2014). The inhomogeneity of $\mathrm{H}$ is evaluated on a fixed grid of points positioned in the bottom of the Petri dish; $\left(f_{1}\right)$ is dimensionless and evaluate the maximum number of points out of the tolerance interval. The $\left(f_{2}\right)$ objective function computes the variation of $\left(f_{1}\right)$ due to a variation of the Petri dish position, for a given device geometry (Di Barba et al., 2014a, b, in press a, b). In the NSGA-DOE algorithm the updating of the design variables is managed by means of a NSGA-II inspired algorithm, whereas the uncertain parameters are taken into account by means of a design of experiment (DOE) strategy. Therefore, NSGA-DOE strategy is a combination of NSGA strategy, to sort the current individuals in local fronts, and DOE strategy, to compute the 
$\mathrm{EC}$

32,7

6

sensitivity $\left(f_{2}\right)$ which in turn is one of the objective function. It is emphasized that uncertain parameters are not coincident with design variables and are used for the computation of the sensitivity of a solution. As far as the third objective function $\left(f_{3}\right)$ two cases have been considered: in the first case, the inductor is supplied by a current of 500 Arms at $350 \mathrm{kHz}$, and $\left(f_{3}\right)$ is the voltage at the inductor ends to be minimized. In fact, the applied voltage should not exceed the typical value made available at the converter output. In the second case the inductor is supplied by a voltage of $600 \mathrm{~V}_{\mathrm{rms}}$ at $350 \mathrm{kHz}$ and $\left(f_{3}\right)$ is the magnetic field value in the bottom of Petri dish to be maximized (typical values are $6-10 \mathrm{kA} / \mathrm{m}$ ). In particular, considering the voltage at the inductor ends as the third objective function makes the optimization problem more oriented to real-life engineering; this way, in fact, the operation of the power supply converter is taken into account. On the other hand, after many numerical experiments, it could be stated that the proposed method of multi-objective optimization is able to deal successfully with more than two objective functions. In both cases the same set of eight design variables is searched for. The eight design variables (Figure 1(a)) are the coil distance from the insulated box, "dR", the size of ferrite block under the box, "HF" and "LF", the vertical distance of the four ferrite blocks from the insulated box, "hf 0 ", "hf $f_{1}$, "hf 2 ", the vertical size of the turns and their gap, "HS" and "ST". In turn, three uncertain parameters are defined as the Petri dish radial position, "DP", the vertical distance of insulated box from lower ferrite, "SPF", and the vertical position of the Petri dish from the insulated box bottom, "HP". Table I reports the design variables and their variation ranges and the nominal values of parameters and the assigned uncertainty range.

The rows of Table II gives the four $\mathrm{Y}_{\mathrm{j}}, j=1, \ldots, 4$, combinations of uncertain parameters to evaluate the sensitivity according to Plackett-Burman DOE strategy (Di Barba et al., 2014; Plackett and Burman, 1946). The “+” and “-” mean the sign alternance of the variation applied to each parameter.

So, given a solution, four $f_{i, j}, j=1, \ldots, 4,\left(f_{i, 1}, f_{i, 2}, f_{i, 3}, f_{i, 4}\right)$ values of the $f_{i}$ objective functions are derived by varying the design variable values as in the following: for the $k$ th uncertain parameter, $k=1,3$, the sums of $f_{i}$ values $\left(f_{i, j}\right)$ corresponding to a " + " in Table I, $S_{+, P k}$, and the ones corresponding to a "-", $S_{-, P k}$, are computed as follows:

$$
\begin{aligned}
& S_{+, P k}=\sum_{j=1}^{4} f_{i, j} \quad Y_{j}=^{\prime}+^{\prime} \\
& S_{-, P k}=\sum_{j=1}^{4} f_{i, j} \quad Y_{j}={ }^{\prime}-^{\prime}
\end{aligned}
$$

\begin{tabular}{lclc}
\hline Design variable & Range $(\mathrm{mm})$ & Uncertain parameters & Nominal value \pm uncertainty range $(\mathrm{mm})$ \\
\hline dR & $(3,10)$ & SPF & $3 \pm 1$ \\
ST & $(0,30)$ & DP & $0 \pm 1$ \\
HS & $(10,60)$ & HP & $3 \pm 1$ \\
LF & $(20,80)$ & & \\
HF & $(5,20)$ & & \\
hf0 & $(1,30)$ & & \\
hf1 & $(1,30)$ & & \\
hf2 & $(1,30)$ & &
\end{tabular}

Table I.

Lower and upper bounds of design variables and nominal values and uncertainty intervals of uncertain parameters 
Then, the influence $s_{P k}$ of a variation of the $k$ th design variable on the value of objective function $f_{i}$ is evaluated as [34]:

$$
s_{P k}=\frac{S_{+, P k}}{N_{+}}-\frac{S_{-, P k}}{N_{-}}
$$

Optimal inductor design

where $\mathrm{N}_{+}$and $\mathrm{N}_{-}$are the number of sign "+" and "-" in the column corresponding to the considered variable in Table I. For the $k$ th design variable the partial sensitivity, $s_{P k}$, is estimated using (13). Finally, the total sensitivity with respect to all the uncertain design variable, $f_{2}$, is given by:

$$
f_{2}=\sqrt{\sum_{k=1}^{3} s_{P k}^{2}}
$$

Under a multi-objective context, $f_{2}$ given by (14) can well be regarded as a secondary objective function in addition to the design criterion $f_{1}$.

\section{Results}

The optimal design results of the magnetic device to heat cell cultures, as well as preliminary experimental results to evaluate the heating of a NP magnetic fluid, are presented.

\subsection{Magnetic device design}

Figure 2 shows an approximation of the 3D Pareto front obtained for the current-supplied model after running a population of 20 individuals for 50 generations. The initial population was randomly generated. The solutions of different runs have been collected.

Figure 3 reports the 2D orthogonal projections of the Pareto front. In Table III a set of solutions on Pareto front are reported. The corresponding geometries are shown in Figure 4.

Figure 5(a) reports the magnetic field strength on the bottom of the Petri dish as a function of position for the cases in Table III. The device geometry with relevant field lines is shown in Figure 5(b) for the solution $\mathrm{S}_{0}$.

Table IV reports the $f_{1}$, named $f_{1}^{*}$, computed with the optimized design variables rounded to the nearest integer. The influence of design variables variation on $f_{1}$ is shown in the Table $V$. The sensitivity of $f_{1}$ is calculated by varying only one design variable at time inside the interval $\pm \mathrm{d}, \mathrm{d}=1 \mathrm{~mm}$ :

$$
\frac{\partial f_{1}}{\partial v_{i}} \cong \frac{f_{1}\left(x_{i}+d\right)-f_{1}\left(x_{i}-d\right)}{2 d}\left[\frac{1}{m m}\right]
$$

\begin{tabular}{lcccc}
\hline & SPF & DP & HP & \\
\hline$Y_{1}$ & + & + & + & $f_{\mathrm{i}, 1}$ \\
$\mathrm{Y}_{2}$ & - & + & - & $f_{\mathrm{i}, 2}$ \\
$\mathrm{Y}_{3}$ & - & - & + & $f_{\mathrm{i}, 3}$ \\
$\mathrm{Y}_{4}$ & + & - & - & $f_{\mathrm{i}, 4}$
\end{tabular}

Table II.

Sign alternance for DOE evaluation of $\mathrm{f}_{2}$ 
EC

32,7

8

Figure 2.

Generated

individuals (gray

points) and

approximated pareto

front (black crosses)

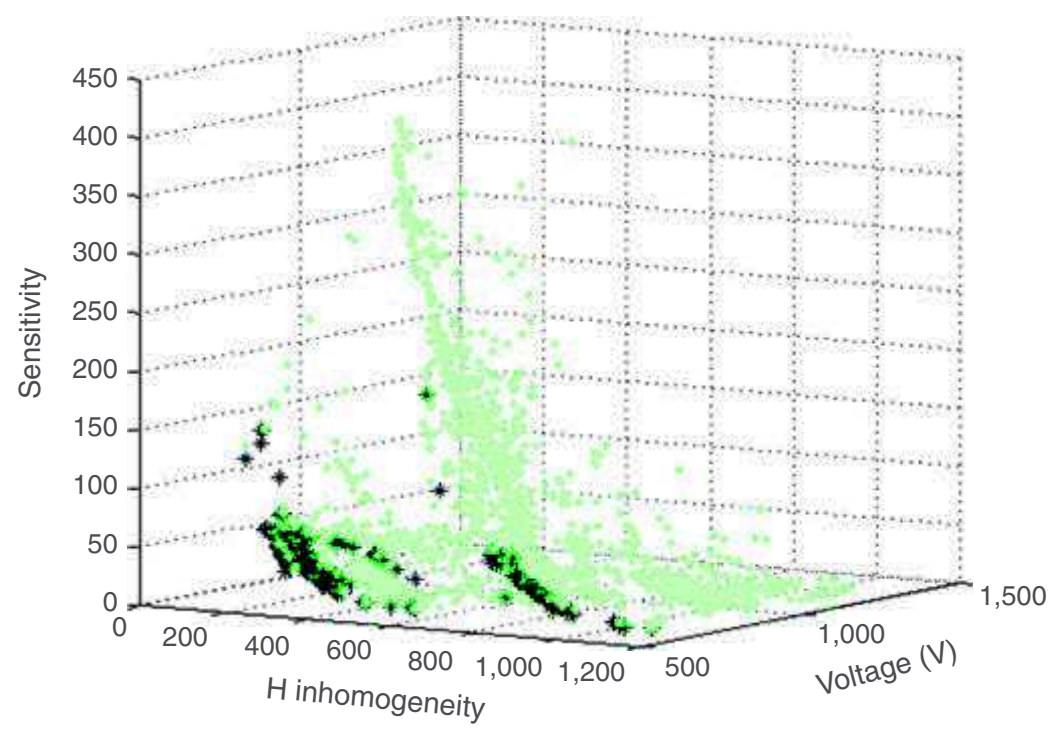

(a)

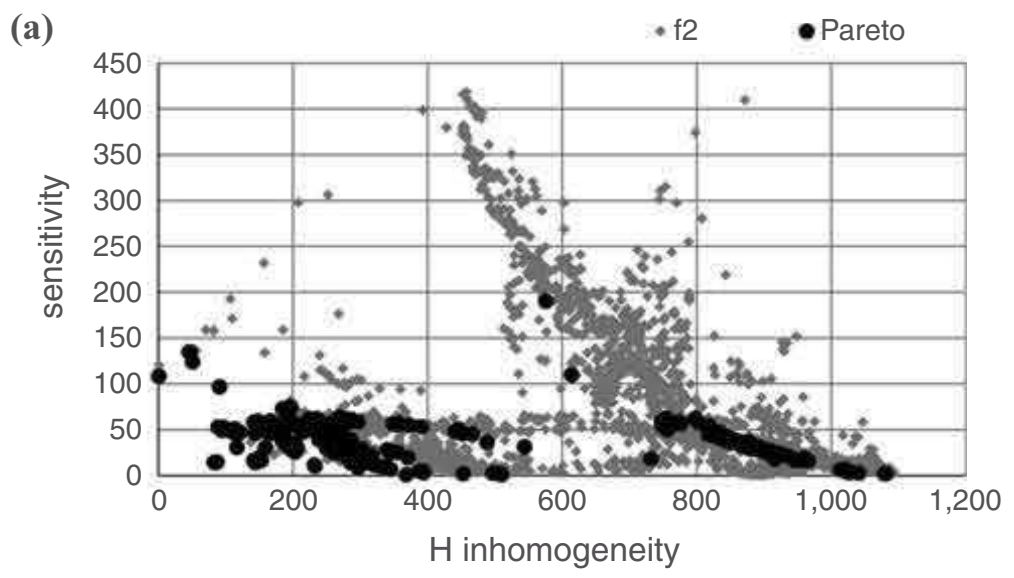

(b)

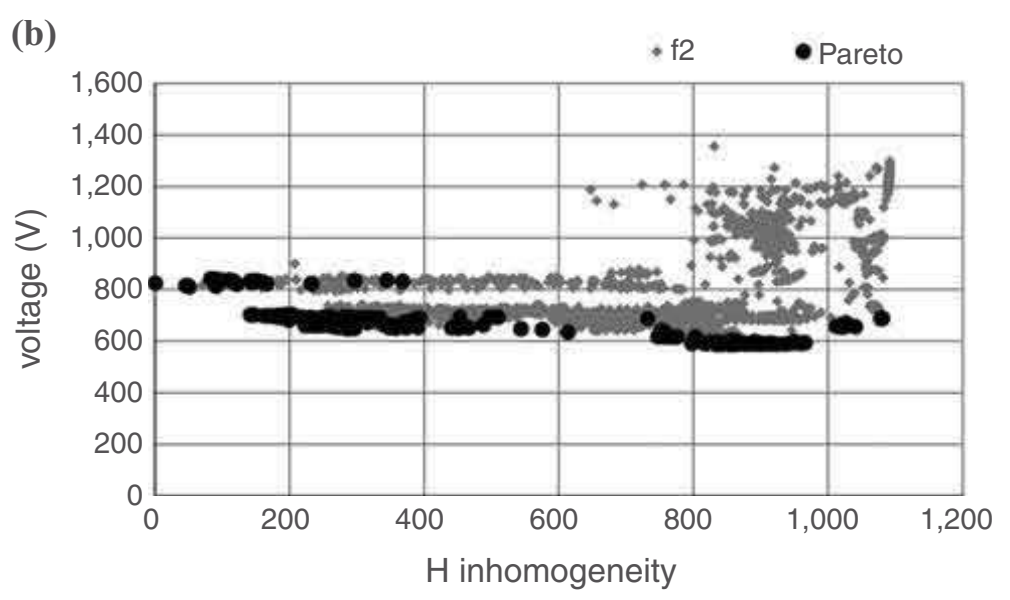

Notes: (a) Sensitivity; (b) voltage vs H inhomogeneity

res: (a) Sensitivity; (b) voltage vs Hinhomogencity
Figure 3.

$2 \mathrm{D}$ projections of pareto fronts 
Figure 6 shows an approximation of the 3D Pareto front obtained for the voltage-supplied model after running a population of 20 individuals for 50 generations. The initial population was random generated. The solutions of different runs have been collected.

Figure 7 reports the 2D orthogonal projections of the Pareto front. In Table V a set of solutions on Pareto front are reported. The corresponding geometries are shown in Figure 8.

Figure 7 (a) reports the magnetic field strength on the bottom of the Petri dish as a function of position for the cases in Table VI. The device geometry with relevant field lines is shown in Figure 9 (b) fort solution $\mathrm{S}_{0}$.

Table VII reports $f_{1}^{*}$, i.e. the values of $f_{1}$ computed with the optimized design variables rounded to the nearest integer. The influence of design variables variation on $f_{1}$ is shown in the Table VIII. The sensitivity of $f_{1}$ is calculated using the (15).

The aim of the proposed multi-objective optimization is to give to the designer the possibility to select the best feasible solutions in terms of field uniformity and solution robustness in accordance with the power supply characteristics. The designer can decide to achieve an excellent field uniformity using a weak solution in terms of sensitivity or vice versa accordingly to the experience in practical realizing such a kind of devices. The final choice depends also on the quality of the available manufacturing technology. A picture of the two-turn inductor which has been realized is shown in Figure 10: the internal diameter of $18 \mathrm{~cm}$.

\section{$5.23 D$ model}

The magnetic field has been sampled along some lines on a ring positioned (internal radius $18 \mathrm{~mm}$, external radius $62 \mathrm{~mm}$ ) in the same position of the Petri dish bottom as in Figure 11.

\begin{tabular}{|c|c|c|c|c|c|c|c|c|c|c|c|}
\hline & $\mathrm{dR}$ & st & LF & $\mathrm{hf}$ & $\mathrm{hf}_{0}$ & $\mathrm{hf}_{1}$ & $\mathrm{hf}_{2}$ & HS & $\mathrm{f}_{1}$ & $\mathrm{f}_{2}$ & $\mathrm{f}_{3}$ \\
\hline S0 & 3.5 & 6.5 & 67.7 & 7.7 & 23.7 & 26.2 & 22.4 & 58.8 & 288 & 60.1 & 647.8 \\
\hline S1 & 4.7 & 30.0 & 43.7 & 5.6 & 24.0 & 26.8 & 18.9 & 59.7 & 819 & 54.4 & 588.6 \\
\hline S2 & 7.8 & 8.9 & 61.0 & 8.6 & 24.5 & 23.8 & 28.6 & 38.0 & 1 & 108.3 & 824.1 \\
\hline S3 & 5.3 & 2.5 & 78.7 & 13.9 & 10.2 & 12.2 & 11.0 & 46.5 & 122 & 47.1 & 819.8 \\
\hline
\end{tabular}

Note: Design variables on [mm], objective function $\mathrm{f}_{1}$ and $\mathrm{f}_{2}$ values dimensionless, $\mathrm{f}_{3}$ in $[\mathrm{V}]$

Table III.

Some solutions on the Pareto front

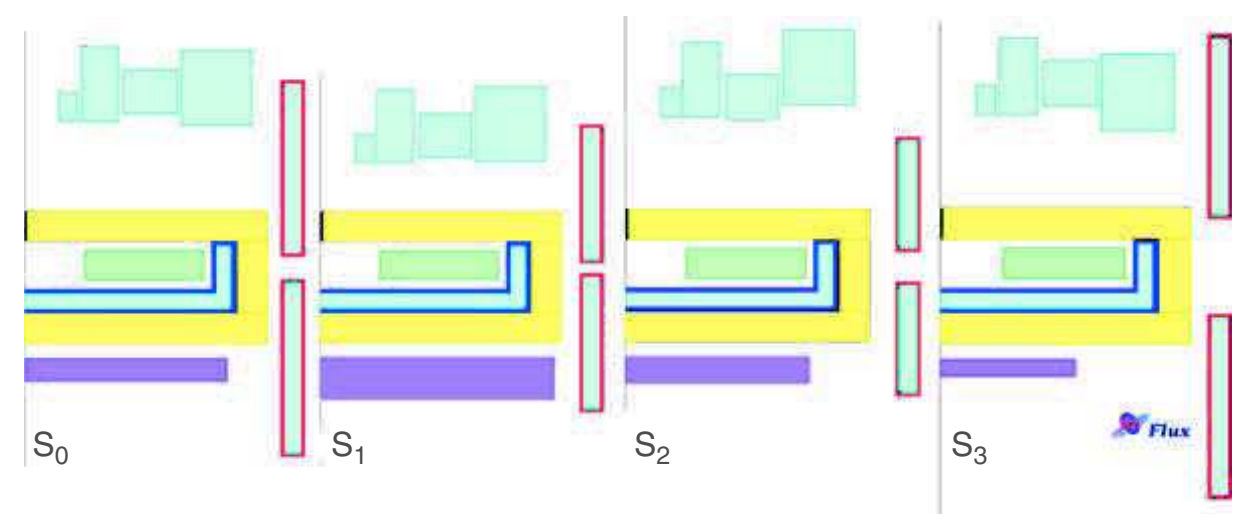

Figure 4.

Geometries of the designed device on pareto front 
EC

32,7

10

Figure 5.

(a) H vs x; (b) field lines of solution $\mathrm{S}_{0}$ (a)

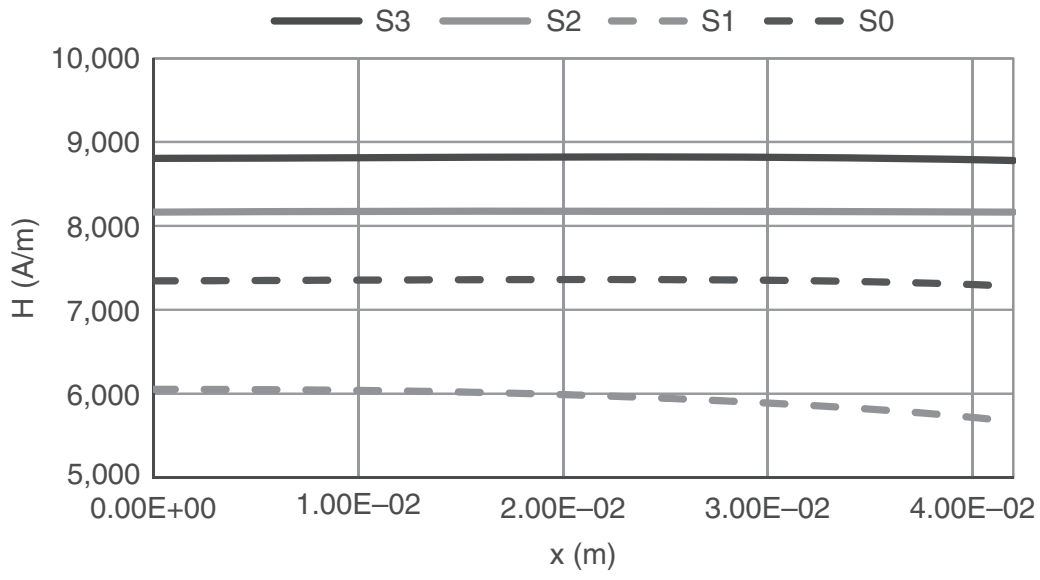

(b)

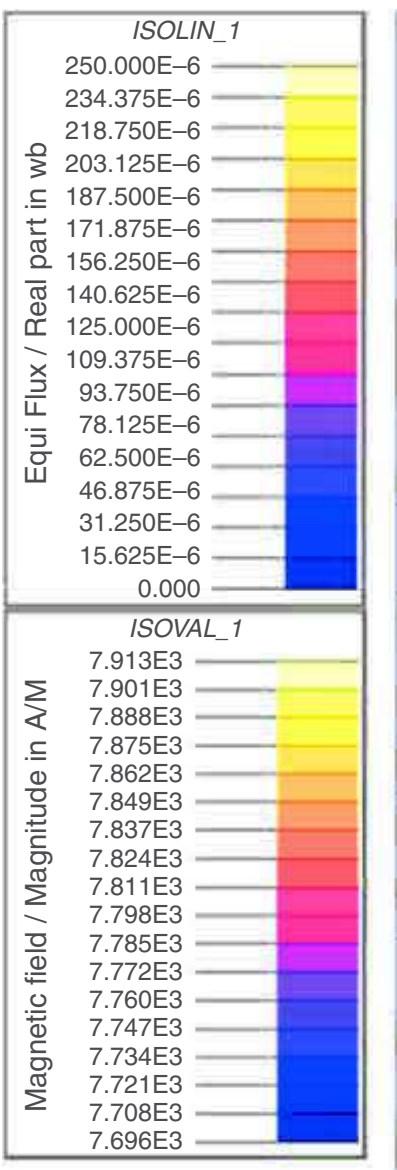

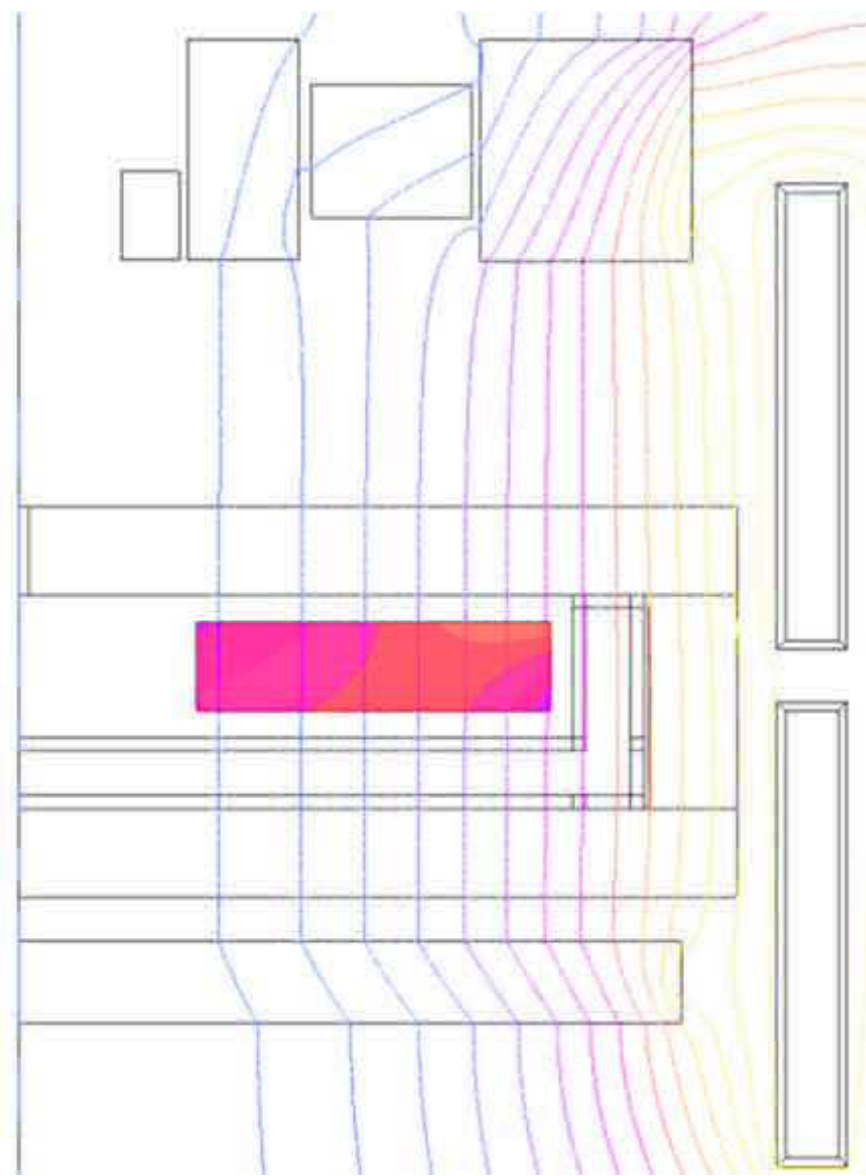

\begin{tabular}{|c|c|c|c|c|c|c|c|c|c|c|}
\hline & $\mathrm{dR}$ & st & LF & hf & $\mathrm{hf}_{0}$ & $\mathrm{hf}_{1}$ & $\mathrm{hf}_{2}$ & HS & $\mathrm{f}_{1}^{*}$ & $\mathrm{f}_{1}-\mathrm{f}_{1}^{*}$ \\
\hline $\mathrm{S}_{0}^{*}$ & 4 & 7 & 68 & 8 & 24 & 26 & 22 & 59 & 315 & -29 \\
\hline $\mathrm{S}_{1}^{*}$ & 5 & 30 & 44 & 6 & 24 & 27 & 19 & 60 & 832 & -12 \\
\hline $\mathrm{S}_{2}^{*}$ & 8 & 9 & 61 & 9 & 25 & 24 & 29 & 38 & 6 & -5 \\
\hline $\mathrm{S}_{3}^{*}$ & 5 & 3 & 79 & 14 & 10 & 12 & 11 & 47 & 154 & -33 \\
\hline
\end{tabular}

Table IV.

$\mathrm{f}_{1}^{*}$ obtained rounding design variables 
Figure 12(a) reports the magnetic field strength along the arcs A and B. Any influence of the inductor tails appears evident. Moreover, any influence to the uniformity of the magnetic field strength due to inductor tails appears along lines from $\mathrm{C}$ to $\mathrm{F}$ (Figure 12(b)).

\subsection{Experimental results}

Before testing the designed inductor to heat cell cultures previously incubated with NPs, a preliminary experiment has been conducted to evaluate the heat generated in different magnetic fluids named samples A, B and C, respectively (Sun et al., 2003; Sun and Zeng, 2002; Bertani et al., 2015, 2010; Sgarbossa et al., 2011; Scaffaro et al., 2011).

Sample A has been prepared by thermal decomposition of iron(III) chloride $\left(\mathrm{FeCl}_{3} \cdot 6 \mathrm{H}_{2} \mathrm{O}\right)$ in 2 -pyrrolidone at $270^{\circ} \mathrm{C}$ for $24 \mathrm{~h}$ according to the method proposed by Li et al. (2005). Similarly, sample B has been synthesized from a 2:1 mixture of iron(III) acetylacetonate ([Fe(acac) 3$])$ and manganese(II) acetylacetonate ([Mn(acac $\left.\left.)_{2}\right]\right)$. Sample $\mathrm{C}$ has been obtained by thermal decomposition of iron(III) acetylacetonate ([Fe(acac) $\left.\left.)_{3}\right]\right)$ in diphenyl ether at $200^{\circ} \mathrm{C}$ for $2 \mathrm{~h}$ and then $300^{\circ} \mathrm{C}$ for $1 \mathrm{~h}$ according to the method developed by Sun et al. (2003) for the preparation of NPs with a diameter of $6 \mathrm{~nm}$. The morphology of the NPs has been investigated by transmission electron microscopy (TEM) analysis using a TECNAI FEI G2 microscope. The magnetic properties of the samples have been detected by means of a RSO-SQUID magnetometer. Magnetization (M) vs temperature (T) measurements have been performed in the 6-300 K range using both in ZFC (zero-field-cooled) and FC (field-cooled) configurations

\begin{tabular}{lcccccccc}
\hline & $\mathrm{dR}$ & $\mathrm{st}$ & $\mathrm{LF}$ & $\mathrm{hf}$ & $\mathrm{hf}_{0}$ & $\mathrm{hf}_{1}$ & $\mathrm{hf}_{2}$ & $\mathrm{HS}$ \\
\hline $\mathrm{S}_{0}$ & -26.5 & -0.5 & 33.5 & 70 & 13 & -76.5 & -15.5 & -6 \\
$\mathrm{~S}_{1}$ & 9.5 & -19 & 37.5 & -29.5 & -0.5 & 42 & 2.5 & -8.5 \\
$\mathrm{~S}_{2}$ & 14 & 0.5 & 50 & 14.5 & -39 & 6 & -30.5 & -25 \\
$\mathrm{~S}_{3}$ & 25 & -30.5 & -2.5 & -109 & -62.5 & 14.5 & 14 & 25.5
\end{tabular}

Table V. sensitivity of $f_{1}^{*}$

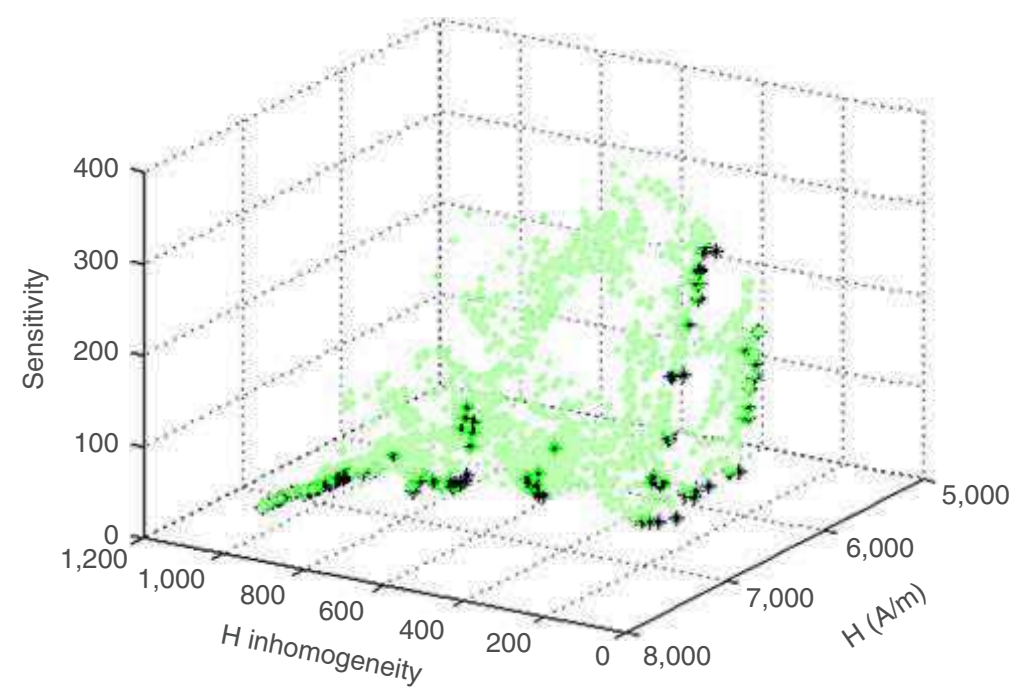

Figure 6. Generated individuals (gray points) and approximated pareto front (black crosses) 
EC

32,7

12

Figure 7.

2D projections of Pareto fronts

Figure 8.

Geometries of the designed device on pareto front
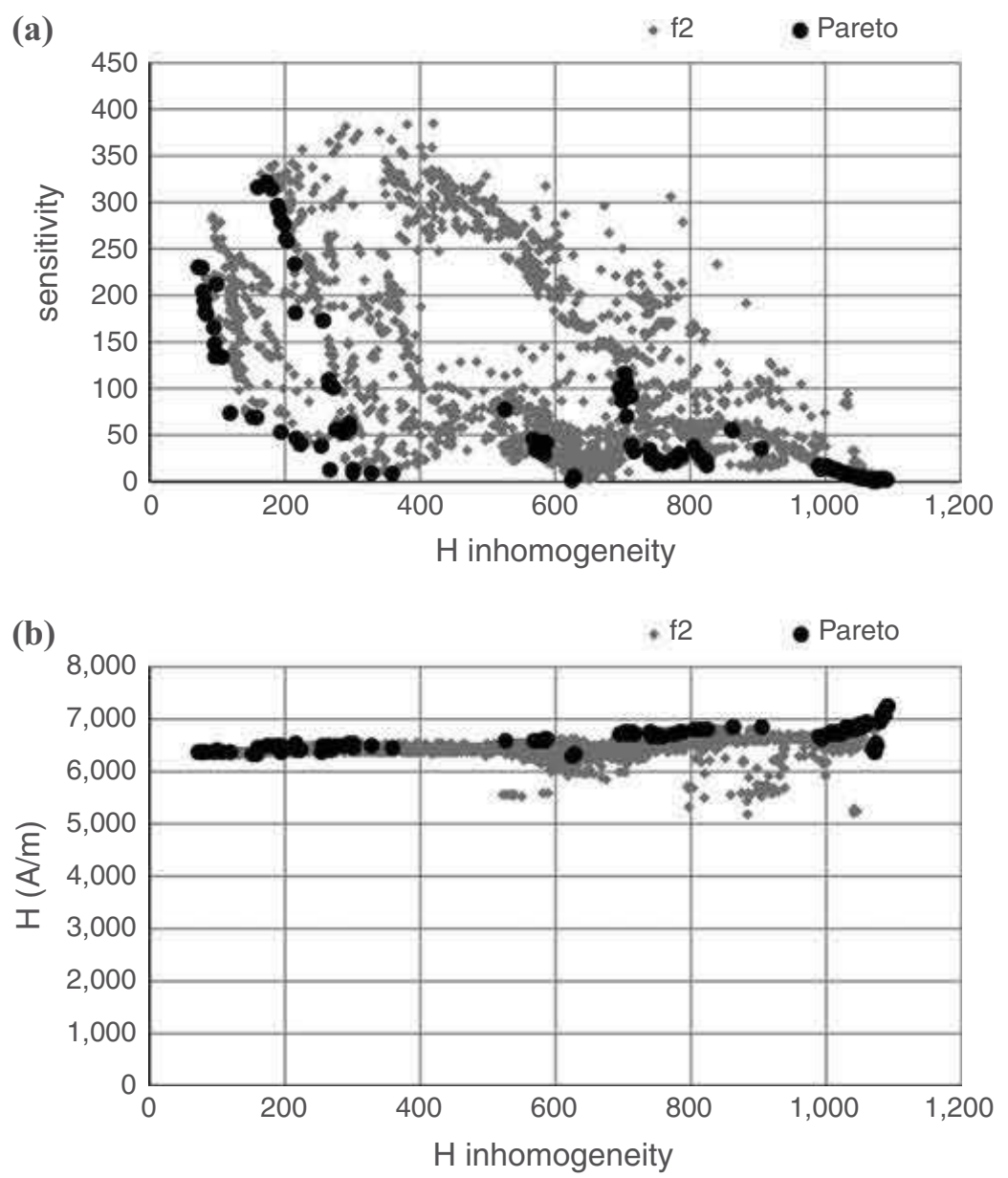

Notes: (a) Sensitivity; (b) magnetic field strength vs $\mathrm{H}$ inhomogeneity

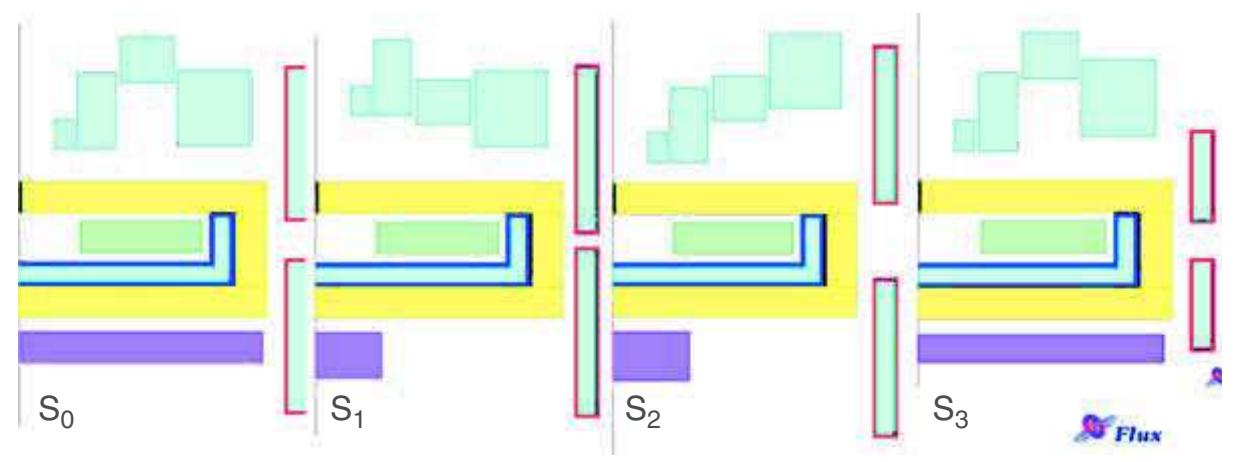

(D'Addato et al., 2010). Magnetization loops were recorded at $300 \mathrm{~K}$. In order to gain indications about the type of magnetic material synthetized, we made resort to Mössbauer spectroscopy (Morais, 2008). Indeed, this technique may probe the chemical, structural and magnetic environment surrounding Fe atoms. Mössbauer data have been collected at room temperature using a ${ }^{57} \mathrm{Co}$ in $\mathrm{Rh}$ source and the spectrometer has been calibrated using an $\alpha$-Fe foil. 
In Figure 13, TEM images show that the NPs of sample A and B are flower-shaped; regarding the NPs of sample $\mathrm{C}$, the majority are spherical, but a small fraction of triangle-shaped NPs are found, as well. Both samples A and B exhibit NPs with a radius close to $12 \mathrm{~nm}$, whereas the average radius of NPs of sample $C$ is about $3 \mathrm{~nm}$. NPs sizes have been estimated using ImageJ software ("ImageJ", n.d.) measuring the diameter of a large number of particles in TEM images; standard deviation is intended as computed on the logarithm of the diameter values according to Rosensweig (2002). The Mössbauer data collected on the different samples are presented in Figure 14(a). The spectrum of sample B clearly shows the presence of a magnetic signal, mainly made of two different sextets; the corresponding hyperfine magnetic fields (HF) are $\mathrm{B}_{\mathrm{HF}, 1}=45.0 \pm 0.1 \mathrm{~T}$ and $\mathrm{B}_{\mathrm{HF}, 2}=48.63 \pm 0.05 \mathrm{~T}$. As this sample was produced using both Fe and Mn diketonates with a 2:1 ratio, for comparison we may use the HF values measured for magnetite (Diamandescu et al., 1998) and for the natural and synthetic Manganese Ferrite (namely Jacobsite, $\mathrm{MnFe}_{2} \mathrm{O}_{4}$ ) (Araujo et al., 1989; Maia et al., 1993). The found $\mathrm{HF}$ values and the relative ratio of the sextets areas are closer to those expected for magnetite, indicating that the NPs relative Mn concentration is smaller than that found in the starting mixture.

In samples $\mathrm{A}$ and $\mathrm{C}$, no sextet structure is found, but just a doublet structure can be observed; regarding sample $\mathrm{C}$, the doublet structure displays a large width, featuring the effects of possible relaxation phenomena. The hyperfine parameters of sample A and $\mathrm{C}$ doublets are in agreement with those found in magnetite, supporting the fact that the NPs are made of magnetite. The absence of sextet structures and the appearance of a doublet structure can be generally traced back to the presence of small size NPs (Spizzo et al., 2004).

Regarding sample $\mathrm{C}$, this observation is in agreement with TEM observations. In the case of sample A, this result may be possibly accounted for considering the presence of the flower-shaped NPs, namely clusters made of smaller NPs. The ZFC-FC measurements of the three samples are presented in Figure 14(b). M vs T data for sample $\mathrm{C}$ show a behavior that resembles the superparamagnetic one, as expected for small sized particles. Differently, in samples A and B the signature of magnetic irreversibility extends up to room temperature, as expected for large particles or for systems where the magnetic size of the particles is large due to interparticle interactions (Allia et al., 2006), as it may happen in flower-shaped NPs. From room temperature magnetization measurements we obtained the bulk saturation magnetization, $M_{d}\left(M_{d}=M[e m u / g] \cdot d\left(\mathrm{~kg} / \mathrm{m}^{3}\right), 1(\mathrm{emu} / \mathrm{g})=1\left(\mathrm{Am}^{2} / \mathrm{kg}\right)\right.$, assuming for magnetite a bulk density, $d$, of $5,180 \mathrm{~kg} / \mathrm{m}^{3}$ and for jacobsite a $4,870 \mathrm{~kg} / \mathrm{m}^{3}$ (Rosensweig, 2002; Haynes, 2014); $M_{d}$ is $109.8 \mathrm{kA} / \mathrm{m}$ for the sample A, $85.5 \mathrm{kA} / \mathrm{m}$ for sample $B$ and $255.9 \mathrm{kA} / \mathrm{m}$ for sample $\mathrm{C}$, whereas the anisotropy constant $\mathrm{K}$ is close to $10.45 \mathrm{~kJ} / \mathrm{m}^{3}$ for the sample A and $126.5 \mathrm{~kJ} / \mathrm{m}^{3}$ for sample $\mathrm{C}$. The strong variation of $\mathrm{K}$ for the three

\begin{tabular}{|c|c|c|c|c|c|c|c|c|c|c|c|}
\hline & $\mathrm{dR}$ & st & LF & hf & $\mathrm{hf}_{0}$ & $\mathrm{hf}_{1}$ & $\mathrm{hf}_{2}$ & HS & $\mathrm{f}_{1}$ & $\mathrm{f}_{2}$ & $\mathrm{f}_{3}$ \\
\hline $\mathrm{S}_{0}$ & 5.1 & 10.9 & 79.9 & 10.2 & 4.6 & 26.6 & 5.8 & 51.1 & 72 & 230.4 & $6,369.4$ \\
\hline $\mathrm{S}_{1}$ & 3.0 & 3.0 & 21.7 & 15.0 & 15.9 & 12.9 & 5.9 & 55.8 & 805 & 37.3 & $6,802.7$ \\
\hline $\mathrm{S}_{2}$ & 4.7 & 23.1 & 25.6 & 16.4 & 1.2 & 14.8 & 19.1 & 53.2 & 1,091 & 1.7 & $7,246.4$ \\
\hline $\mathrm{S}_{3}$ & 4.7 & 9.9 & 78.5 & 8.8 & 3.4 & 26.5 & 8.0 & 29.9 & 359 & 8.2 & $6,451.6$ \\
\hline
\end{tabular}

Note: Design variables on $[\mathrm{mm}]$, objective functions $\mathrm{f}_{1}$ and $\mathrm{f}_{2}$ dimensionless, $\mathrm{f}_{3}$ in $[\mathrm{A} / \mathrm{m}]$

Table VI.

Some solutions on pareto front 
EC

32,7

14

Figure 9.

(a) $\mathrm{H}$ vs x; (b) field

lines of solution $\mathrm{S}_{0}$ (a)

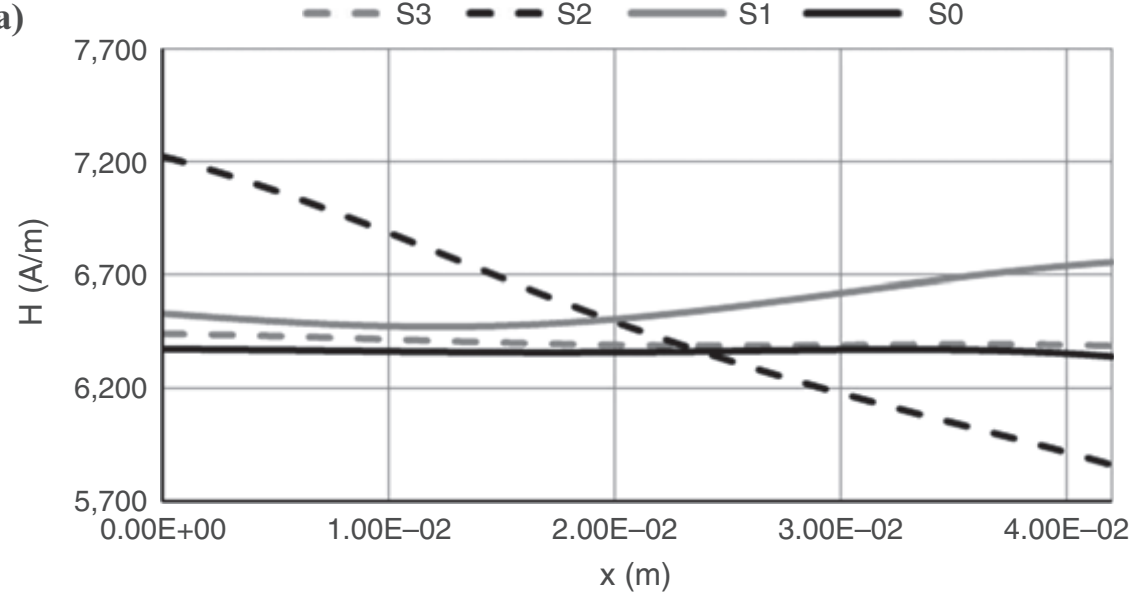

(b)

(b) ISOVAL 1

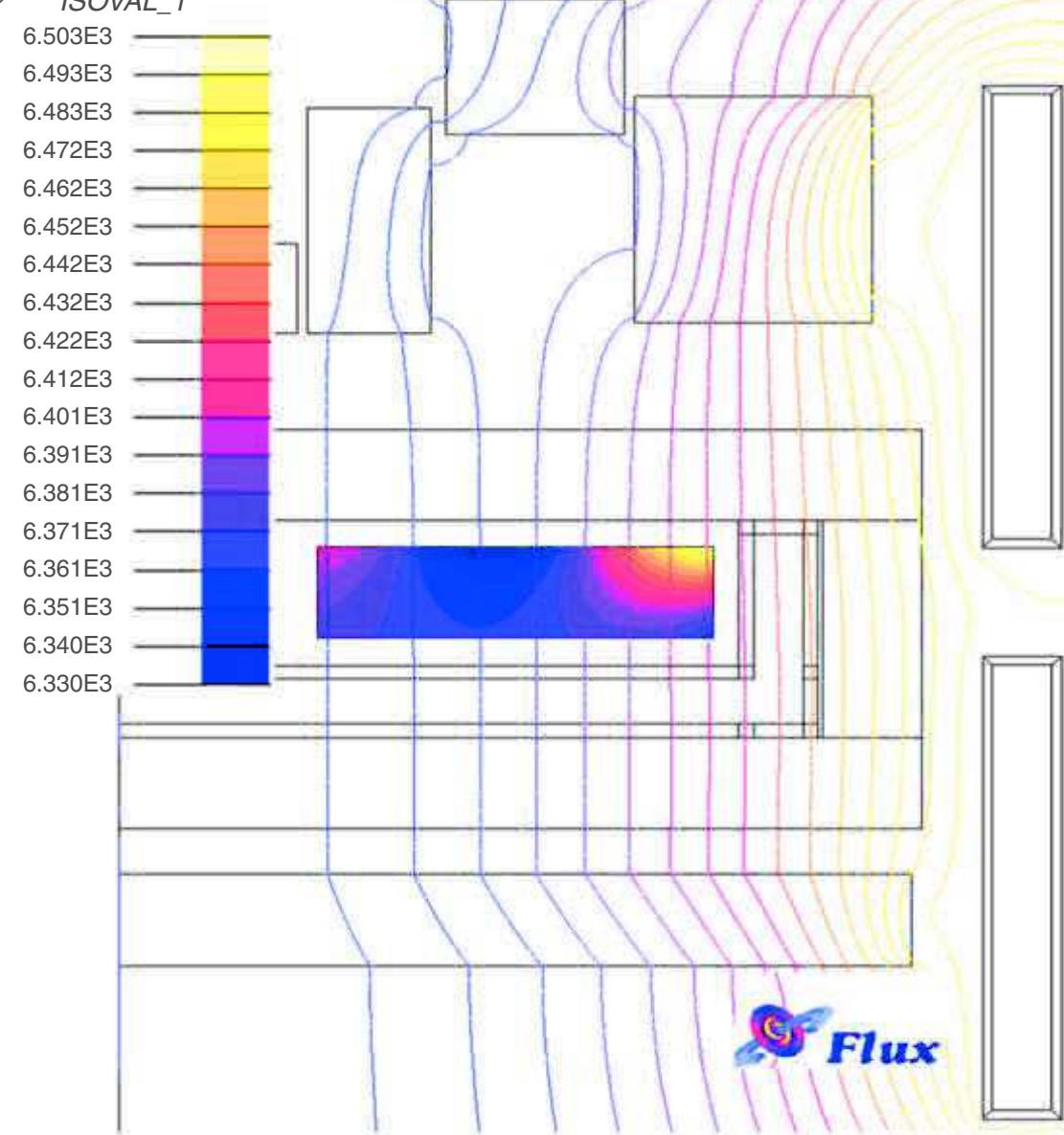

\begin{tabular}{|c|c|c|c|c|c|c|c|c|c|c|}
\hline & $\mathrm{dR}$ & st & LF & hf & $\mathrm{hf}_{0}$ & $\mathrm{hf}_{1}$ & $\mathrm{hf}_{2}$ & HS & $\mathrm{f}_{1}^{*}$ & $\mathrm{f}_{1}-\mathrm{f}_{1}^{*}$ \\
\hline $\mathrm{S}_{0}^{*}$ & 5 & 11 & 80 & 10 & 5 & 27 & 6 & 51 & 101 & -29 \\
\hline $\mathrm{S}_{1}^{*}$ & 3 & 3 & 22 & 15 & 16 & 13 & 6 & 56 & 803 & 3 \\
\hline $\mathrm{S}_{2}^{*}$ & 5 & 23 & 26 & 16 & 1 & 15 & 19 & 53 & 1,091 & 0 \\
\hline $\mathrm{S}_{3}^{*}$ & 5 & 10 & 79 & 9 & 3 & 27 & 8 & 30 & 373 & -9 \\
\hline
\end{tabular}


samples may be interpreted as a signature of the presence of interparticle magnetic interactions (Allia and Tiberto, 2011). The sample A was suspended in water that has a viscosity close to $0.001 \mathrm{Pas}$, whereas the sample $\mathrm{C}$ is dispersed in PEG 400 with a viscosity of $90 \mathrm{mPa}$. Both sample $\mathrm{A}$ and $\mathrm{C}$ have a volume fraction $\phi$ of 0.0019 (10 $\mathrm{mg}$ of powder was dispersed in each $\mathrm{ml}$ of suspension fluid, $\left.\phi=(\mathrm{mg} / \mathrm{ml}) / d\left(\mathrm{~kg} / \mathrm{m}^{3}\right)\right)$, whereas for sample B $\phi$ is 0.0021 . The data of the NP samples are summarized in Table IX.

The power density generated by NP suspensions was evaluated before applying them to cell cultures. A sample of $2 \mathrm{ml}$ of a water suspension (NP concentration: $10 \mathrm{mg} / \mathrm{ml}$ ) placed in a test tube was subjected for $5 \mathrm{~min}$ to a magnetic field (maximum intensity $13.6 \mathrm{kA} / \mathrm{m}$ at $177 \mathrm{kHz}$, current of $300 \mathrm{Arms}$ ) generated by means of a cylindrical inductor with seven turns, $8 \mathrm{~cm}$ internal diameter, connected to an EASYHEAT LI

\begin{tabular}{|c|c|c|c|c|c|c|c|c|c|}
\hline & $\mathrm{dR}$ & st & $\mathrm{LF}$ & hf & $\mathrm{hf}_{0}$ & $\mathrm{hf}_{1}$ & $\mathrm{hf}_{2}$ & HS & \\
\hline $\mathrm{S}_{0}^{*}$ & -24 & -39.5 & 12.5 & 7.5 & 64.5 & 48.5 & -27 & -23.5 & \\
\hline $\mathrm{S}_{1}^{*}$ & -5.5 & -4 & -7 & 2 & 3 & 11 & -16.5 & 1 & \\
\hline $\mathrm{S}_{2}^{*}$ & -1.5 & 1 & 0 & 0 & -1 & 0 & 1 & 0 & Table VIII. \\
\hline $\mathrm{S}_{3}^{*}$ & -12 & 49 & -1.5 & -0.5 & -114 & -91 & 70.5 & 39 & sensitivity of $\mathrm{f}_{1}^{*}$ \\
\hline
\end{tabular}

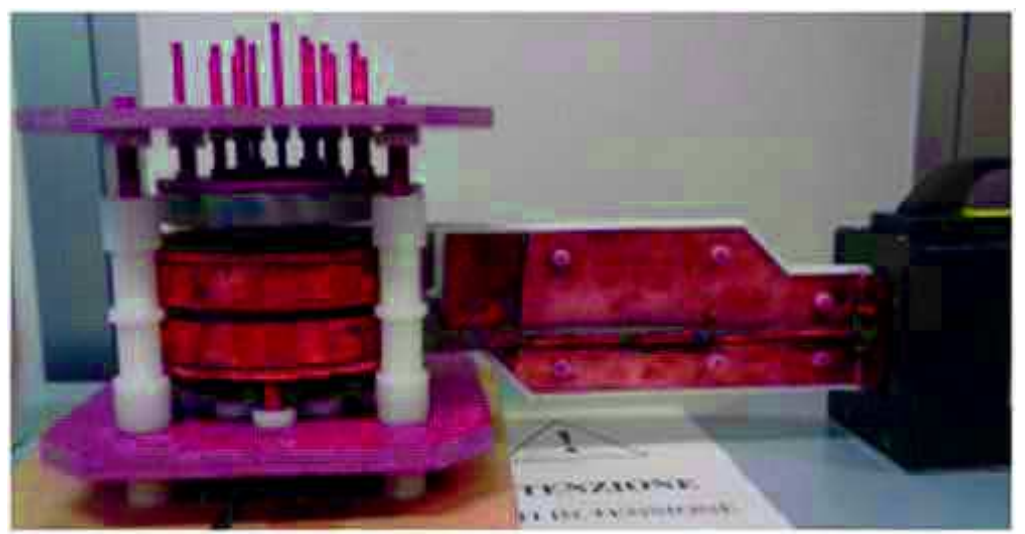

Q10

Figure 10.

Realized inductor for Petri dish experiments

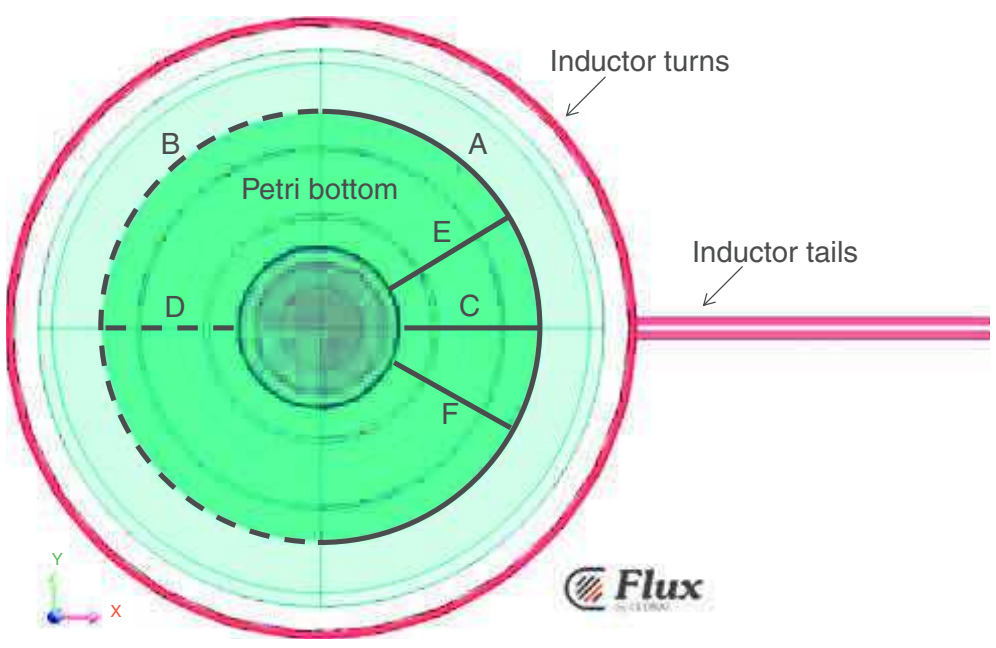

Figure 11. $\mathrm{XY}$ section of the 3D geometry and position of the lines where the magnetic field has been sampled 
EC

32,7

16

Figure 12.

Magnetic field strength
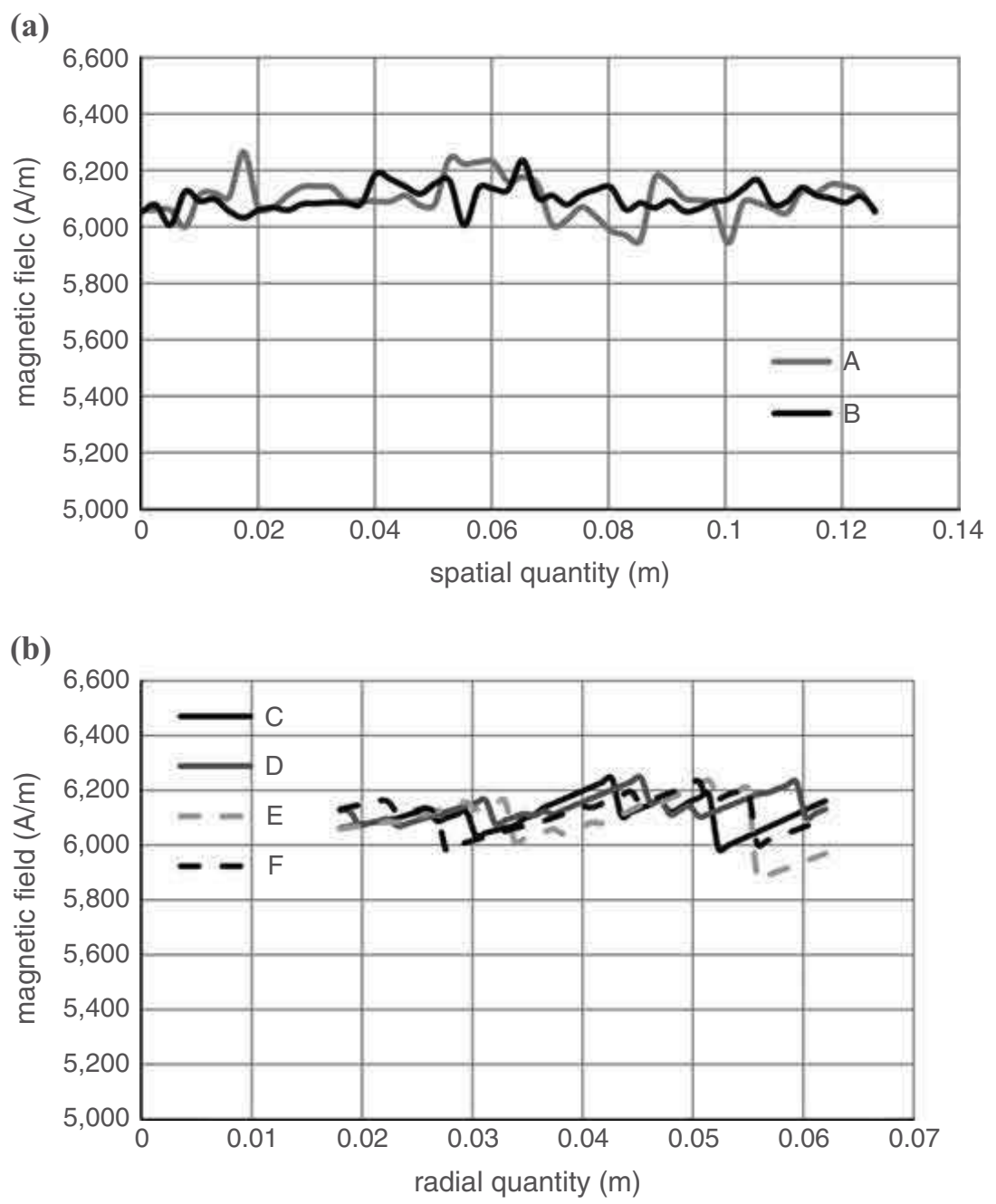

Notes: (a) Arc A and B; (b) along lines from C to F (Figure 10)

5,060 converter (Figure 15) or a two turns $18 \mathrm{~cm}$ internal diameter (Figure 10). Temperature was measured by means of an Optocom Fotemp-1H thermometer with a TS3/2 fiber optic.

The experimental heating rate has been estimated as the ratio between the temperature increasing, $\Delta \mathrm{T}(\mathrm{K})$, occurred during the experiment and the time interval of the magnetic field application, $\Delta \mathrm{t}(\mathrm{s})$ :

$$
H R_{m}=\frac{\Delta T}{\Delta t}(K / s)
$$

The heating rate obtained using (12) has been compared with the expected one, $H R_{c}$, estimated in adiabatic conditions according to Fortin et al. (2007) and Rosensweig (2002) from the power density $P$, in $\left(\mathrm{W} / \mathrm{m}^{3}\right)$, computed using (1) and taking into account the polydispersion of NPs radii as in Fortin et al. (2007) and Rosensweig (2002):

$$
H R_{c}=\frac{P}{d \cdot c}(K / s)
$$


(a)

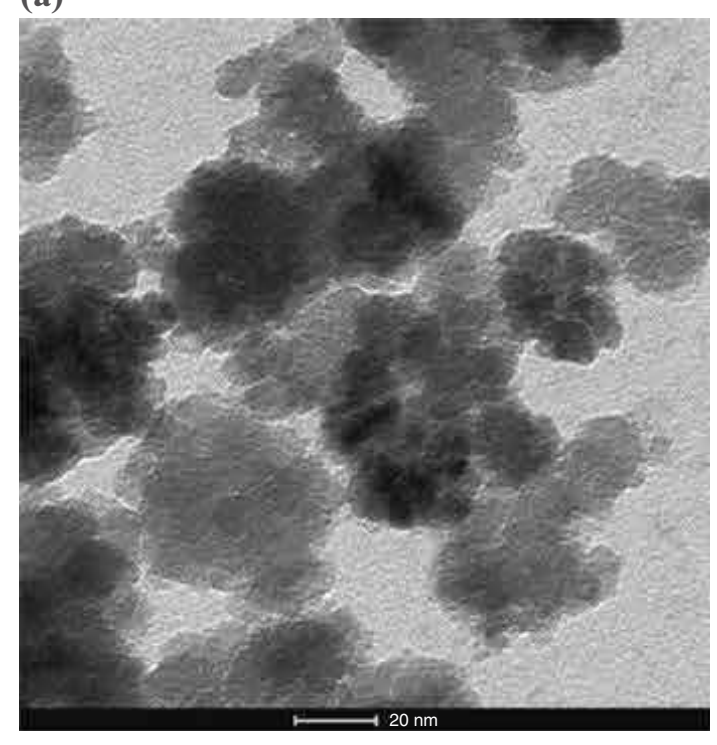

(b)

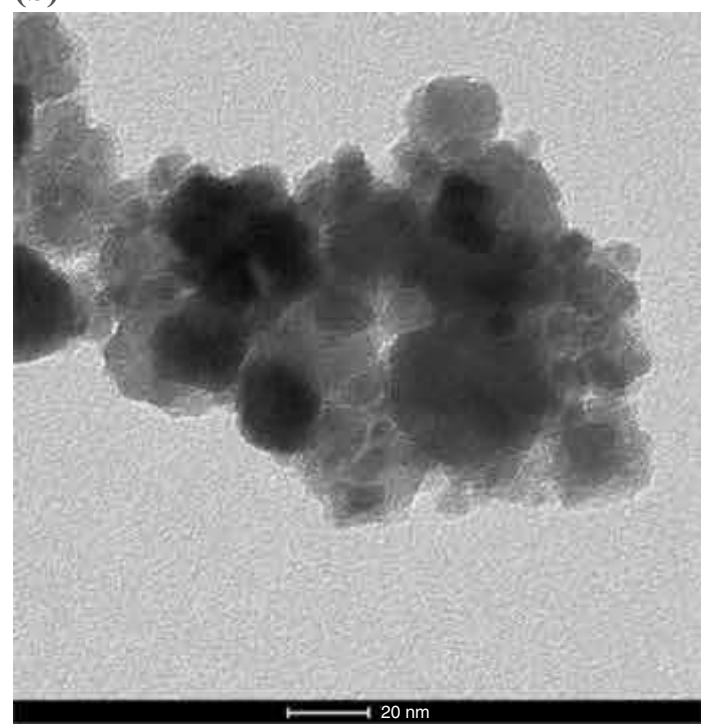

Optimal inductor design

(c)

Figure 13. NPs shape $\mathrm{x}$

Notes: (a) Sample A; (b) sample B; (c) sample C

where $c$ and $d$ are, respectively, the specific heat $(\mathrm{J} /(\mathrm{kg} \mathrm{K}))$ and the density $\left(\mathrm{kg} / \mathrm{m}^{3}\right)$ of the suspension fluid. In this case the density of the magnetic nanofluid has been approximated with the one of the suspension fluid as in Fortin et al. (2007). The measured and computed temperature increasing for the sample described in Table IX are presented in Table X. Figure 16 shows the heating rate (17) for the sample $\mathrm{A}, \mathrm{B}$ and sample $\mathrm{C}$ as a function of the NPs radius considering the nanofluid characteristics of Table IX. The dot represents the computed heating rate for the NPs with the radius in Table IX.

The temperature increasing produced in a $4 \mathrm{ml} \mathrm{NP}$ suspensions (sample B) in a Petri dish with a diameter of $3 \mathrm{~cm}$ has been measured for 5 min applying a magnetic field (using the inductor in Figure 10 with a maximum magnetic field strength 
$\mathrm{EC}$

32,7

18

of $6.3 \mathrm{kA} / \mathrm{m}$ at $240 \mathrm{kHz}$ (supply current $450 \mathrm{Arms}$ ) or $7.8 \mathrm{kA} / \mathrm{m}$ at $240 \mathrm{kHz}$ (supply current 500 Arms)). In the preliminary experiment with Petri dish no thermal insulation has been used; therefore, the heating rate has not been computed because measurements have not been conducted in adiabatic conditions. In this preliminary experiment $3 \mathrm{ml}$ of nanofluid has been put in the Petri dish.

From reported data it appears that suspensions prepared using synthetized NPs are promising to heat cells.

(a)

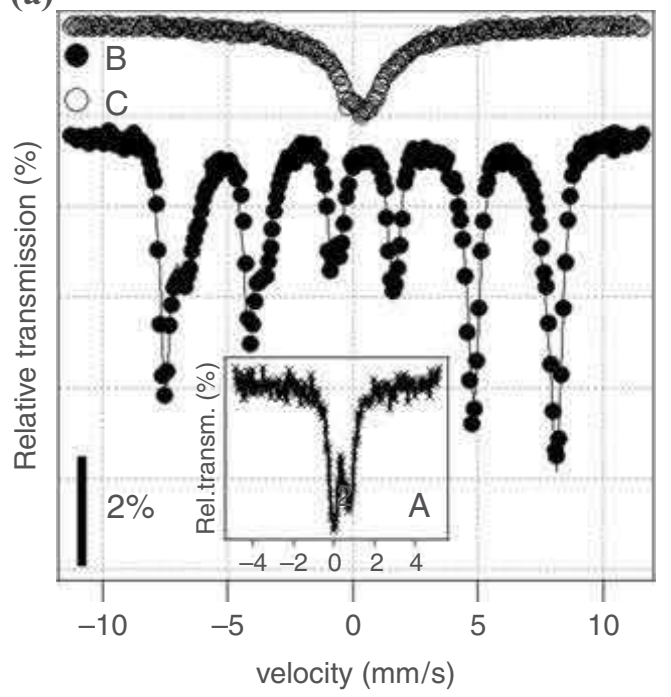

(b)

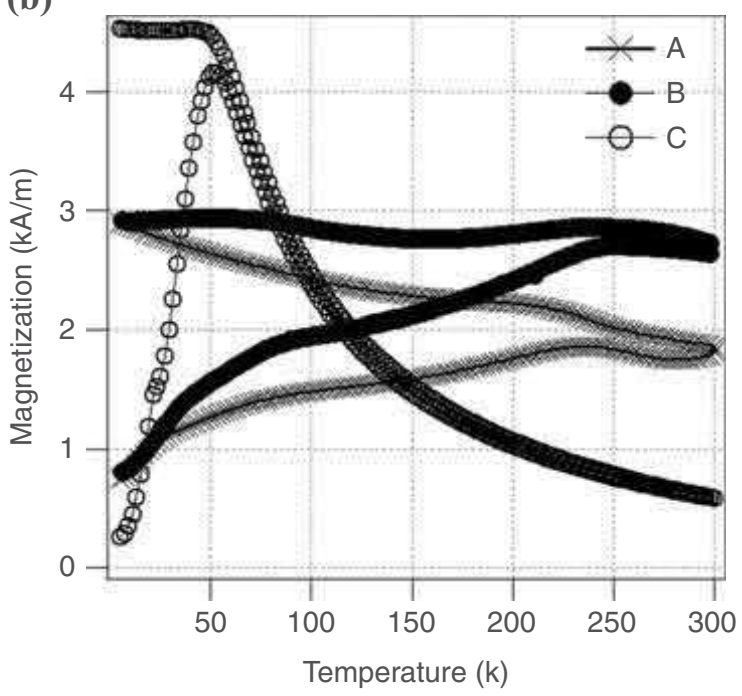

Figure 14.

(a) Mössbauer spectra of samples A (in the inset),

$\mathrm{B}$ and $\mathrm{C}$; the straight line reported on $\mathrm{B}$ sample data is a fit performed according to the model described in the text (b) $\mathrm{ZFC}$ and $\mathrm{FC}$ magnetization measurements of samples $\mathrm{A}, \mathrm{B}$ and $\mathrm{C}$

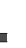
. 


\section{Conclusion}

Numerical models coupled with optimization algorithms have been applied to the robust design of an electromagnetic device able to produce a uniform magnetic field in a prescribed region. Some preliminary experiments have been also carried out in order to exploit the required performance of the system, in order to properly heat magnetic nanofluids. Finally, the designed device has been realized and tested.
Optimal inductor design

\begin{tabular}{lcccccc}
\hline Sample & $\mathrm{H}(\mathrm{kA} / \mathrm{m})$ & $\mathrm{F}(\mathrm{kHz})$ & $\mathrm{HR}_{\mathrm{c}}(\mathrm{K} / \mathrm{s})$ & $\mathrm{HR}_{\mathrm{m}}(\mathrm{K} / \mathrm{s})$ & $\Delta \mathrm{T}_{\mathrm{c}}(\mathrm{K})$ & $\Delta \mathrm{T}_{\mathrm{m}}(\mathrm{K})$ \\
\hline A & 13.6 & 177 & 0.049 & 0.036 & 14.7 & 10.8 \\
B_1 & 13.6 & 177 & 0.03 & 0.067 & 9 & 20 \\
C & 13.6 & 177 & 0.004 & 0.00033 & 1.2 & 0.1 \\
B_2 & 6.3 & 240 & 0.009 & 0.009 & 2.7 & 2.7 \\
B_3 & 7.8 & 240 & 0.013 & 0.012 & 3.9 & 3.7
\end{tabular}

Note: Temperature measurements related to sample B_2 and B_3 are performed putting $3 \mathrm{ml}$ of nanofluid $(10 \mathrm{mg} / \mathrm{ml})$ in a Petri dish

Table X.

Experimental results (a)

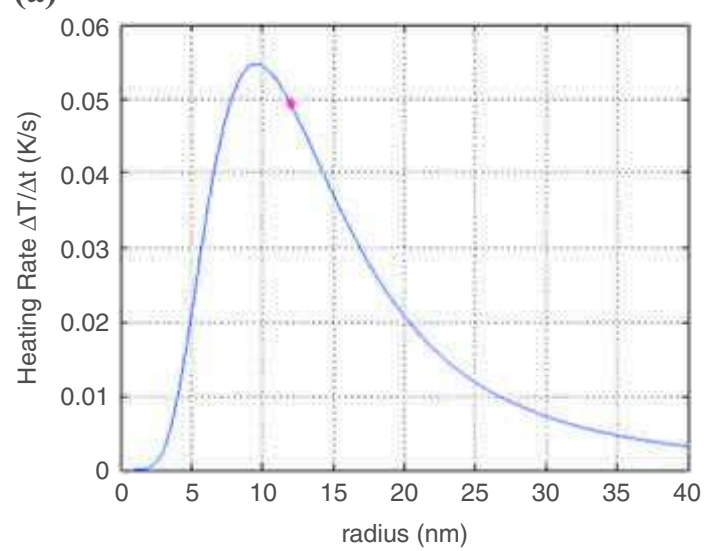

(b)

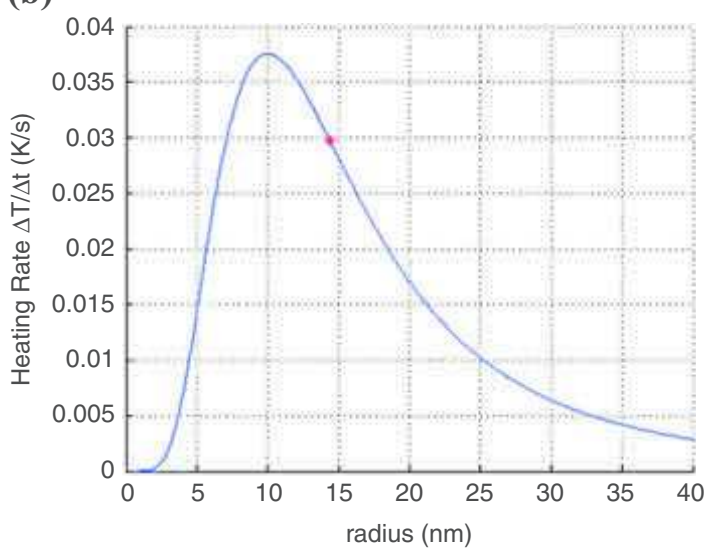

(c)

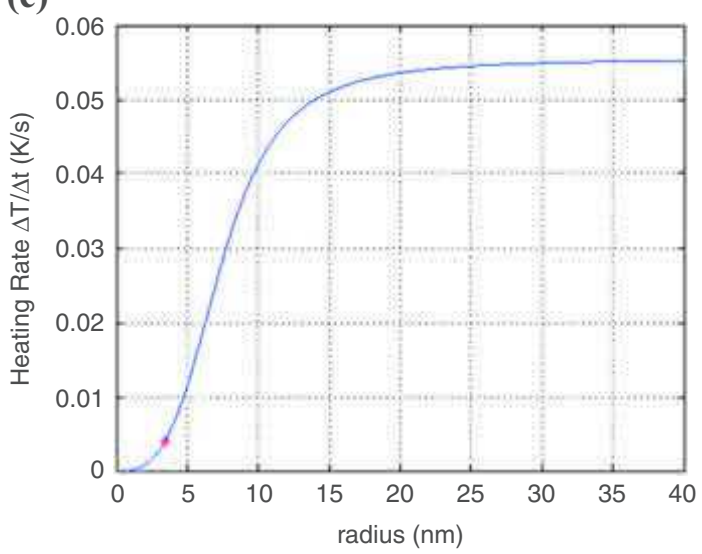

Notes: (a) Sample A; (b) sample B; (c) sample C

Figure 16.

Heating rate computed using (13) as a function of nanoparticle radii 
$\mathrm{EC}$

32,7

20

Q3

\section{References}

Aliferov, A., Dughiero, F. and Forzan, M. (2010), "Coupled magneto-thermal FEM model of direct heating of ferromagnetic bended tubes", Magnetics, IEEE Transactions on, Vol. 46 No. 8, pp. 3217-3220.

Allia, P. and Tiberto, P. (2011), "Dynamic effects of dipolar interactions on the magnetic behavior of magnetite nanoparticles”, Journal of Nanoparticle Research, Vol. 13 No. 12, pp. 7277-7293.

Allia, P., Coisson, M., Spizzo, F., Tiberto, P. and Vinai, F. (2006), "Magnetic correlation states in cosputtered granular Ag100-xFex films”, Physical Review B, Vol. 73 No. 5, doi:10.1103/ PhysRevB.73.054409.

Araujo, M.A.B., de, Costa, T.V.V., Lima, M.C.A., Maia, H.A. and Vieira, V.W. (1989), "Thermal transformations of natural jacobsite (Mn, Fe) ${ }_{3} \mathrm{O}_{4}$ ”, Physica Scripta, Vol. 40 No. 5, pp. 682-684.

Barba, P.D., Pleshivtsera, Y., Raport, E., Forzan, M., Lupi, S., Sieni, E., Nacke, B., et at. (2013), "Multi-objective optimisation of induction heating processes: methods of the problem solution and examples based on benchmark model", International Journal of Microstructure and Materials Properties, Vol. 8 No. 4, pp. 357-372.

Bertani, R., Ceretta, F., Dughiero, F., Forzan, M., Gandin, V., Marzano, C., Michelin, R., et at. (2015), "Synthesis, characterization and application of iron oxide magnetic nanoparticles for magneto fluid hyperthermia therapy", in Lacković, I. and Vasic, D. (Eds), 6th European Conference of the International Federation for Medical and Biological Engineering, IFMBE Proceedings, Vol. 45, Springer International Publishing, pp. 329-332.

Bertani, R., Sgarbessa, P., Venzo, A., Lelj, F., Amati, M., Resnati, G., Pilati, T., et at. (2010), "Halogen bonding in metal-organic-supramolecular networks", A Tribute to Fausto Calderazzo on the Occasion of his 80th Birthday, Vol. 254 Nos 5/6, pp. 677-695.

Binns, K.J., Lawrenson, P.J. and Trowbridge, C.W. (1992), The Analytical and Numerical Solution of Electric and Magnetic Fields, Wiley, Chichester.

Biro, O., Preis, K., Buchgraber, G. and Ticar, I. (2004), "Voltage-driven coils in finite-element formulations using a current vector and a magnetic scalar potential", Magnetics, IEEE Transactions on, Vol. 40 No. 2, pp. 1286-1289.

P’Addato, S., Gragnaniello, L., Valeri, S., Rota, A., di Bena, A., Spizzo, F., Panozaqi, T., et at.(2010), "Morphology and magnetic properties of size-selected Ni nanoparticle films", Journal of Applied Physics, Vol. 107 No. 10, p. 104318.

Di Barba, P., Dughiero, F. and Sieni, E. (2012a), "Field synthesis for the optimal treatment planning in magnetic fluid hyperthermia”, Archives of Electrical Engineering, Vol. 61 No. 1, pp. 57-67.

Di Barba, P., Dughiero, F. and Sieni, E. (2012b), "Synthesizing distributions of magnetic nanoparticles for clinical hyperthermia”, Magnetics, IEEE Transactions on, Vol. 48 No. 2, pp. 263-266.

Di Barba, P., Dughiero, F. and Sieni, E. (2012c), "Non-parametric optimal shape design of a magnetic device for biomedical applications", COMPEL - The International Journal for Computation and Mathematics in Electrical and Electronic Engineering, Vol. 31 No. 5, pp. 1358-1367.

Di Barba, P., Dughiero, F. and Sieni, E. (2013), "Parameter-free paretian optimisation in electromagnetics: a kinematic formulation", Science, Measurement \& Technology, IET, Vol. 7 No. 2, pp. 93-103.

Di Barba, P., Forzan, M. and Sieni, E. (2014b), "Multi-objective design of a power inductor: a benchmark problem of inverse induction heating", in Doležel, I. (Ed.), Compel - The International Journal for Computation and Mathematics in Electrical and Electronic Engineering, Vol. 33 No. 6, pp. 1990-2005. 
Di Barba, P., Forzan, M. and Sieni, E. (in press a), "Multiobjective design optimization of an induction heating device: a benchmark problem", International Journal of Applied Electromagnetics and Mechanics.

Di Barba, P., Savini, A. and Wiak, S. (2008), Field Models in Electricity and Magnetism, Springer, Dordrecht.

Di Barba, P.D., Dughiero, F. and Sieni, E. (2010), "Magnetic field synthesis in the design of inductors for magnetic fluid hyperthermia”, Magnetics, IEEE Transactions on, Vol. 46 No. 8, pp. 2931-2934.

Di Barba, P., Dughiero, F., Forzan, M. and Sieni, E. (2014a), "A paretian approach to optimal design with uncertainties: application in induction heating”, Magnetics, IEEE Transactions on, Vol. 50 No. 2, pp. 917-920.

Di Barba, P., Dughiero, F., Forzan, M. and Sieni, E. (mess b), "Sensitivity-based optimal shape design of induction-heating devices", IET Sci. Meas. Technol.

Di Barba, P., Forzan, M., Pozza, C. and Sieni, E. (2012), "Optimal design of a pancake inductor for induction heating: A multiphysics and multiobjective approach", Proc CEFC.

Diamandescu, L., Mihăilă-Tărăbăşanu, D., Teodorescu, V. and Popescu-Pogrion, N. (1998), "Hydrothermal synthesis and structural characterization of some substituted magnetites", Materials Letters, Vol. 37 No. 6, pp. 340-348.

Q8 FLUX (n.d.), “(CEDRAT)”, available at: www.cedrat.com/software/flux/flux.html (accessed Oetober 2014).

Fortin, J.P., Wilhelm, C., Servais, J., Menager, C., Bacri, J.C. and Gazeau, F. (2007), "Size-sorted anionic iron oxide nanomagnets as colloidal mediators for magnetic hyperthermia”, Journal of the American Chemical Society, Vol. 129 No. 9, pp. 2628-2635.

Gneveckow, U., Jordan, A., Scholz, R., Brüss, V., Waldöfner, N., Ricke, J., Feussner, A., Hildebrandt, B., Rau, B. and Wust, P. (2004), "Description and characterization of the novel hyperthermia- and thermoablation-system MFH 300F for clinical magnetic fluid hyperthermia.", Med Phys, Vol. 31 No. 6, pp. 1444-1451.

Goya, G.F., Asín, L. and Ibarra, M.R. (2013), "Cell death induced by AC magnetic fields and magnetic nanoparticles: current state and perspectives", International Journal of Hyperthermia, Vol. 29 No. 8, pp. 810-818.

Goya, G.F., Berquó, T.S., Fonseca, F.C. and Morales, M.P. (2003), "Static and dynamic magnetic properties of spherical magnetite nanoparticles", Journal of Applied Physics, Vol. 94 No. 5, pp. 3520-3528.

Haynes, W.M. (2014), CRC handbook of chemistry and physics: a ready-reference book of chemical and physical data.

Hildebrandt, B., Wust, P., Ahters, $Q$., Dieing, A., Sreenirasa, G., Kerner, T., Felix, R., et at. (2002), "The cellular and molecular basis of hyperthermia", Critical Reviews in Oncology/Hematology, Vol. 43 No. 1, pp. 33-56.

“ImageJ" (n.d.), available at: http://imagej.nih.gov/ij/ (accessed Oeter 2014).

Jordan, A.S.R. (1999), "Endocytosis of dextran and silan-coated magnetite nanoparticles and the effect of intracellular hyperthermia on human mammary carcinoma cells in vitro", J. Magn. Magn. Mater., Vol. 194 Nos 1/3, p. 185.

Jordan, A., Seholz, R., Maier Hauff, K., Johannsen, M., Wust, P., Nadobny, J., Sehirra, H., et at. (2001), "Presentation of a new magnetic field therapy system for the treatment of human solid tumors with magnetic fluid hyperthermia", Journal of Magnetism and Magnetic Materials, Vol. 225 Nos 1/2, pp. 118-126.

Jordan, A., Scholz, R., Wust, P., Fahling, H. and Felix, R. (1999), "Magnetic fluid hyperthermia (MFH): cancer treatment with $\mathrm{AC}$ magnetic field induced excitation of biocompatible superparamagnetic nanoparticles", Journal of Magnetism and Magnetic Materials, Vol. 201 Nos 1/3, pp. 413-419. 
$\mathrm{EC}$

32,7

Krishnan, K.M. (2010), "Biomedical nanomagnetics: a spin through possibilities in imaging, diagnostics, and therapy”, IEEE Transactions on Magnetics, Vol. 46 No. 7, pp. 2523-2558.

Li, Z., Sun, Q. and Gao, M. (2005), "Preparation of water-soluble magnetite nanocrystals from hydrated ferric salts in 2-pyrrolidone: mechanism leading to Fe3O4", Angewandte Chemie, Vol. 117 No. 1, pp. 125-128.

Maia, H.A., De Araújo, F.F.T., De Araújo, M.A.B., Danon, J. and Frankel, R.B. (1993), “Cation distribution in natural ferrites", Hyperfine Interactions, Vol. 77 No. 1, pp. 43-50.

Meunier, G. (Ed.) (2008), The Finite Element Method for Electromagnetic Modeling, ISTE, Wiley, London, Hoboken, NJ.

Morais, P.C. (2008), "Using mössbauer spectroscopy as key technique in the investigation of nanosized magnetic particles for drug delivery", Hyperfine Interactions, Vol. 181 Nos 1/3, pp. 1-12.

Plackett, R.L. and Burman, J.P. (1946), "The design of optimum multifactorial experiments", Biometrika, Vol. 33 No. 4, pp. 305-325.

Riganti Fulginei, F. and Salvini, A. (2007), "Comparative analysis between modern heuristics and hybrid algorithms", in Martone, R. (Ed.), Compel - The International Journal for Computation and Mathematics in Electrical and Electronic Engineering, Vol. 26 No. 2, pp. 259-268.

Roca, A.G, Costo, R., Rebolledo, A.F., Veintemillas-Verdaguer, S., Tartaj, P., González-Carreño, T., Morales, M.P. and Serna, C.J. (2009), "Progress in the preparation of magnetic nanoparticles for applications in biomedicine", Journal of Physics D: Applied Physics, Vol. 42 No. 22, p. 224002.

Rosensweig, R.E. (2002), "Heating magnetic fluid with alternating magnetic field”, J. Magn. Magn. Mater., Vol. 252 Nos 1/3 p. 370.

Scaffaro, R., Botta, L., Lo Re, G., Bertani, R., Milani, R. and Sassi, A. (2011), "Surface modification of poly(ethylene-co-acrylic acid) with amino-functionalized silica nanoparticles", Journal of Materials Chemistry, Vol. 21 No. 11, pp. 3849-3857.

Sgarbossa, P., Bertani, R., Di Noto, V., Piga, M., Giffin, G.A., Terraneo, G., Pilati, T., et al. (2011), "Interplay between structural and dielectric features of new low $\mathrm{k}$ hybrid organicorganometallic supramolecular ribbons", Crystal Growth \& Design, Vol. 12 No. 1, pp. 297-305.

Spizzo, F., Angeli, E., Bisero, D., Da Re, A., Ronconi, F. and Vavassori, P. (2004), "Mössbauer investigation of sputtered FexAg100-x films", Proceedings of the International Conference on Magnetism (ICM 2003), Vols 272/276 Part 2, pp. 1169-1170.

Sun, S. and Zeng, H. (2002), "Size controlled synthesis of magnetite nanoparticles", J. Am. Chem. Soc., Vol. 124 No. 28, p. 8204.

Sun, S., Zeng, H., Robinson, D.B., Raoux, S., Rice, P.M., Wang, S.X. and Li, G. (2003), "Monodisperse MFe2O4 ( $\mathrm{M}=\mathrm{Fe}, \mathrm{Co}, \mathrm{Mn})$ nanoparticles", Journal of the American Chemical Society, Vol. 126 No. 1, pp. 273-279.

Wolpert, D.H. and Macready, W.G. (1997), "No free lunch theorems for optimization", IEEE Transactions on Evolutionary Computation, Vol. 1 No. 1, pp. 67-82.

\section{About the authors}

Professor Roberta Bertani had her graduation in Chemistry at the Padova University in 1980 discussing a thesis dealing with the migration of ancillary ligand in the coordination sphere of palladium(II) systems. From 1/12/1982 to 31/10/1998 was a researcher in the Center of organometallic Chemistry of Transition Metals of CNR, of which was the Director starting from 1992 to 2002. From 1/11/1998 Roberta Bertani is Associated Professor in Chemistry at the Faculty of Engineering of the University of Padova teaching Chemistry for InformationEngineering, Chemistry and Materials for Electronics, Chemical Bases of Technologies for Mechanical, Energy and Aerospace Engineering. Coordinated and participated to many national and international programs. Roberta Bertani is co-author of more than 170 between papers and patents in the fields of interest. 
Dr Flavio Ceretta received his MS (2009) degrees and his PhD (2013) in chemical engineering from the University of Padova, Italy. Currently he has a post-doctoral fellowship at the Department of Industrial Engineering of the University of Padova. His research interests include synthesis and functionalization of fluorinated compounds and nanostructured materials for industrial and medical applications.

Professor Paolo Di Barba, $\mathrm{PhD}$ was born in Italy in 1963. At the time being, he is appointed as a Full Professor of Electrical Engineering at the University of Pavia, Department of Electrical, Computer and Biomedical Engineering. His scientific interests include the computer-aided design of electric and magnetic devices, with special emphasis on the methods for field synthesis. He authored or co-authored more than 100 papers, either presented to international conferences or published in international journals, a book on "Field Models in Electricity and Magnetism" (Springer, 2008) and a monograph on "Multiobejctive Shape Design in Electricity and Magnetism" (Springer, 2010).

Professor Fabrizio Dughiero was born in 1964. From 1991 was Assistant Researcher, from 1998 Associate Professor at the Catania university and 1999 Associate Professor at the Padova University. From 2012 is Full Professor at the Padova University. He is currently teaching "Electrical Engineering" for the Bachelor Course of Energy Engineering and Electroheat of the master course of Electrical engineering. His main scientific interests are in the field of Electroheat and in particular in its applications in the industrial and domestic background. He is author of more than 130 papers presented at international conferences or published in ISI journal and $\mathrm{He}$ is coauthor of 6 patents in the field of induction heating.

Professor Michele Forzan Graduated in Electrical Engineering in 1995 and received the "Dottorato di Ricerca" in 2000 at the University of Padova, under the direction of Professor Sergio Lupi. From 2003 he is Assistant Professor at the Electrical Engineering Department. His research activity have been mainly devoted to the study of innovative electro heat processes and to the development of numerical models for the design of induction heating systems.

Rino Antonio Michelin was Full Professor of Chemical Foundations of Technologies at the Department of Industrial Engineering at the University of Padova. He graduated in Chemistry at the University of Padua. He was researcher at the National Research Council, postdoctoral associate at the Iowa state university and associate professor of chemistry. His research activity mainly concerns the synthesis and the study of the reactivity and catalytic activity of organometallic compounds and transition metal coordination.

Dr Paolo Sgarbossa is a Researcher at the Department of Industrial Engineering at the University of Padova since october 2007. He completed his $\mathrm{PhD}$ in 2006 at the same University, under the supervision of Professor Rino A. Michelin, working on the synthesis of new Pt-based homogeneous catalysts for the oxidation of organic compounds. His main research interests are: synthesis and characterization of Pt(II) and Pd(II) complexes for catalytic and biological applications and magnetic nanoparticles for hyperthermia.

Dr Elisabetta Sieni received the Degree in Electronic Engineering, $\mathrm{PhD}$ in Bioelectromagnetics and Electromagnetic Compatibility and $\mathrm{PhD}$ in Information Engeneering, Bioengineering, from the Padova University, respectively, in 2002, 2006 and 2011. Actually she is working at the Department of Electrical Engineering of the Padova University with a post-Doc. Her interests are in human exposure to electromagnetic field, optimization and biomedical application of electromagnetic fields. Dr Elisabetta Sieni is the corresponding author and can be contacted at: elisabetta.sieni@unipd.it

Dr Federico Spizzo works at the Department of Physics and Earth Sciences of the University of Ferrara, and his main interest is the investigation of the magnetic properties of nanostructured magnetic systems. He started his activity studying systems made of magnetic nanoparticles, combining magnetic and structural techniques to focus on the effects of interparticle magnetic interactions. Then he also investigated the exchange interaction between ferromagnetic and antiferromagnetic phases in continuous films and dot arrays, to assess size confinement effects.

For instructions on how to order reprints of this article, please visit our website:

www.emeraldgrouppublishing.com/licensing/reprints.htm

Or contact us for further details: permissions@emeraldinsight.com 